\title{
VICENTE SALVADOR GÓMEZ, ALONSO CANO Y LA PINTURA VALENCIANA DE LA SEGUNDA MITAD DEL SIGLO XVII
}

\author{
POR \\ SALVADOR SALORT PONS \\ Real Colegio de Esspaña en Bolonia \\ M. JOSÉ LÓPEZ AZORÍN \\ BENITO NAVARRETE PRIETO \\ Universidad de Valladolid
}

In the following pages, we study different unpublished documentation on the saga of valencian painters of last name Salvador. It is, fundamentally, the last will and inventory of goods of Vicente Salvador Gómez, the contract that he carried out with the Convent of Santo Domingo of Valencia, for the realisation of three paintings on San Vicente's Ferrer life, and other notarial texts related with him, his father Pere and his brother Luciano that will allow us to better understand the biography and the pictorial work of this family of artists. In addition, the fact of having located the one mentioned inventory, dated after the purchase that Vicente Salvador made of the belongings left by Alonso Cano in the Chartreuse of Portacoeli of Valencia, will give us the opportunity to know, in some measure, the goods that Cano possessed in 1645, among them his library that, for the first time, it is published. Finally, with the study of several of Vicente's Salvador drawings we will be able to determine some og his labour bonds with the Madrid nobility, as well as to support the theory of his possible trip to Italy.

La pintura valenciana del siglo XVII es aún una de las grandes desconocidas de la historia del arte español. Hasta la fecha, las investigaciones, a este respecto, se han centrado en estudiar, principalmente, el periodo inicial de la pintura barroca valenciana, debido a su importancia en el panorama artístico español del final del siglo xvı y principios del xvir. Entonces, los pintores valencianos marcaban la pauta en lo que a «modernidad» e innovación estética se refería, en relación con los otros maestros que, en la península Ibérica, se incorporaban a las nuevas corrientes pictóricas.

Este momento de florecimiento artístico tiene su origen en la llegada a Valencia del patriarca Ribera, fundador del Colegio del Corpus Christi, quien supo reunir en torno suyo a un grupo de artistas capaces de interpretar la doctrina tridentina con un nuevo lenguaje pictórico que reaccionaba, desde la estética naturalista, contra la formas heredadas del Renacimiento Italiano. De todos los pintores protegidos por Ribera, fueron singulares Francisco Ribalta y su hijo 
Juan, cuyos principios artísticos, pioneros en su tiempo, perduraron en la ciudad, a lo largo de todo el siglo XVII, gracias a las actividades de otros pintores como Jerónimo Jacinto Espinosa y Vicente Salvador Gómez, que encarnaron y desarrollaron, de forma clara y fiel, el estilo

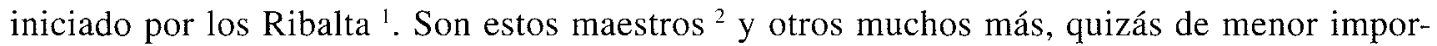
tancia pero no por ello de menor interés, a los que todavía no se les ha dedicado un estudio riguroso y pormenorizado que incluya un trabajo de búsqueda de obras y de documentación archivística, con el fin de ofrecer un panorama claro de la pintura valenciana del segundo y tercer tercio del siglo XVII.

En este sentido, nuestra intención va a ser, en las siguientes páginas, dar a conocer y estudiar diferente documentación inédita sobre la saga de pintores valencianos de apellido Salvador. Se trata, fundamentalmente, del testamento e inventario de bienes de Vicente Salvador Gómez, el contrato que éste llevó a cabo con el Convento de Santo Domingo de Valencia, para la realización de sus famosas pinturas, y otros textos notariales relacionados con el propio Vicente, su padre Pere y su hermano Luciano, que nos permitirán establecer, con mayor precisión, la biografía y las realizaciones pictóricas, de esta familia de artistas. Asimismo, el hecho de haber localizado el citado inventario, fechado después de la compra que Vicente Salvador hizo de la pertenencias dejadas por Alonso Cano en la Cartuja de Portacoeli de Valencia ${ }^{3}$, nos va a dar la oportunidad de conocer, en alguna medida, los bienes que Cano poseía en $1645^{4}$, entre ellos su biblioteca que, por primera vez, se publica. Finalmente, con el estudio de varios de los dibujos de Vicente Salvador podremos determinar algunos de sus vínculos laborales con la nobleza madrileña, así como apoyar la teoría de su posible viaje a Italia.

Las principales fuentes históricas para el conocimiento de la pintura valenciana son los libros de Ponz, Orellana y Ceán. En ellos, por lo que concierne a Vicente Salvador Gómez y su hermano Luciano, encontramos pocas noticias biográficas, generalmente imprecisas, y abundantes referencias a obras que dejaron en diferentes instituciones religiosas y en manos de privados. Estas obras, hoy en día, por las desamortizaciones, las pérdidas de la Guerra Civil y los incontrolados depósitos que el Museo San Pío V de Valencia hizo en el pasado, son difíciles y, en muchos casos, imposibles de localizar.

Sabemos que Vicente Salvador Gómez nació en 1637, de Pere Salvador y de Elena Gómez, y que fue bautizado en Valencia, en la iglesia de San Martín y no en la de San Juan como apuntó Orellana ${ }^{5}$. De su padre Pere Salvador, también pintor, tenemos noticia de que había realizado diversas obras en las puertas del altar mayor y en la sacristía de la parroquial de Bocairente y que su estilo se podía vincular, según Tormo, a la escuela de Juanes ${ }^{6}$. A la actividad artística de Pere Salvador, podemos añadir que pintó, en 1655, para el Convento de San Ignacio de

\footnotetext{
' Caso a parte es el de José de Ribera que, como es sabido, nació en Játiva pero su formación pictórica se desarrolló en Italia, país en el que residió gran parte de su vida.

${ }^{2}$ A este respecto se debe recordar el pionero trabajo de A.E. Pérez Sánchez, Jerónimo Jacinto de Espinosa, Madrid 1972.

${ }^{3}$ Navarrete Prieto, B., «Sobre Vicente Salvador Gómez y Alonso Cano: Nuevos documentos y fuentes formales», Ars Longa, 6, 1996, pp. 135-40.

${ }^{4}$ Una primera aproximación sobre la biblioteca de Alonso Cano se puede leer en B. Navarrete Prieto, La pintura andaluza del Siglo XVII y sus fuentes grabadas, Madrid 1998, pp. 70 y 71.

${ }^{5}$ B. Navarrete Prieto, «Obra cit». Ars Longa, 1996, p. 135-6. Navarrete señala que el año de la carta de bautismo de Salvador coincide con la edad que el pintor declara tener en 1674, 37 años. Asimismo, pone en evidencia la relación entre la parroquia de San Martín y V. Salvador en la que, no sólo fue bautizado sino que también, pintó el lienzo del altar mayor. Como apuntó Adela Espinós, este lienzo desaparecido en la Guerra Civil, quizá tenga su boceto preparatorio en el dibujo del mismo asunto atribuido por Angulo y Pérez Sánchez al valenciano. Véase E. Tormo, Levante, Valencia 1923, p. 115; D. Angulo \& A. Pérez Sánchez, A corpus of Spanish drawings. Valencia 1600 - 1700 London 1988, p.77, dibujo n. 394.

'Pérez Sánchez fue el primero en poner en relación a Pere Salvador con Vicente Salvador, A. Pérez Sánchez, «Vicente Salvador Gómez: a propósito de una obra adquirida por el Prado», Boletín del Museo del Prado, 2, 1980, pp. 69-78. Alcahalí, Diccionario biográfico de artistas valencianos, Valencia, 1897, p. 296. E. Tormo. Levante, Guías Regionales Calpe, Madrid, 1923, p. 263.
} 
Rubielos de Mora (Teruel) tres lienzos: uno de San Felipe Neri y dos para-los resaltes del altar que representaban a San Ignacio y a Santa Teresa de Jesús ${ }^{7}$. El hecho de que Pere Salvador trabajase en Bocairente y en Rubielos, nos permiten definirlo, en una primera hipótesis, como un pintor itinerante por las diversas poblaciones más o menos cercanas a la capital levantina, en donde seguramente tendría su taller, pues el mismo se declaraba, ante notario," «Pintor de Valencia».

Como es lógico pensar, los primeros pasos de Vicente Salvador'en el ejercicio de la pintura los debió dar con su propio padre. Sin embargo, las fuentes refieren que Vicente se formó con Jerónimo Jacinto de Espinosa y, no cabe duda, de que el estilo de aquél, sobre todo en sus obras de juventud, es plenamente deudor del de éste. Es posible sospechar, a este respecto, que siendo el joven Vicente muy precoz en el arte de la pintura - Orellanaáfirma que con tan sólo 14 años pintó una serie de lienzos de la vida de San Ignacio en la caśa profesa de Valenciael padre quiso que se formara con el pintor de mayor prestigio en la ciudad, como lo era, en aquel momento, Espinosa.

En cuanto a esta serie de San Ignacio, hoy en el Museo San Pío V de Valencia, el Dr. García Mahiques ha demostrado que los cuadros, aunque están directamente vinculados al estilo de Espinosa, son, en verdad, de mano de Vicente Salvador. Para su composición, apunta Mahiques, utilizó algunos de los grabados de Cornelis Galle, Theodor Galle, Adrian Collaert y Karel Mallery, que ilustraban la Vita Beati Patris Ignatii de Ribadeneyra, publicada por primera vez en Amberes en $1610^{8}$. Con respecto a todo ello, no nos parece imposible pensar que pudiera haber una estrecha relación, probablemente de tipo laboral y de colaboración, entre los Salvador, Espinosa y la Compañía de Jesús, ya que algunos años antes de que Vicente realizara la citada serie, Jerónimo Jacinto había llevado a cabo varios lienzos para la misma compañía y el propio Pere Salvador en 1656, como hemos visto, pintó tres cuadros para el Convento de San Ignacio de Rubielos de Mora.

Creemos que el encargo que Vicente Salvador recibió en 1651, es decir con 14 años, tuvo que ser supervisado por el propio Espinosa, ya que el análisis estilístico de las obras y la adolescencia del muchacho así lo hacen lógico pensar. Durante los años que siguieron al encargo de los Jesuitas, debió permanecer colaborando y aprendiendo en el taller de su maestro, por lo menos hasta 1663, fecha en la que, seguramente, ya era un pintor independiente. Tal y como hemos podido saber, el 9 de diciembre de aquel año, Salvador se declara «pictor cuius urbis Valentia» al obligarse, con la Iglesia de Predicadores de Valencia (Convento de Santo Domingo), a pintar «de sa ma propia» cuatro cuadros de la vida de San Vicente Ferrer: la aparición de la hermana del santo cuando éste celebraba misa en la Iglesia de Predicadores, la muerte de San Vicente Ferrer, la restitución de la corona, por parte del santo, al rey $D$. Fernando y la profecía de San Vicente en la plaza del Born de Barcelona, de la llegada milagrosa de las naves.

Los cuatro lienzos, que iban a decorar la capilla de San Vicente Ferrer, debían tener distintos tamaños y asimismo tenían que entregarse en diferentes momentos. Los dos primeros, actualmente en paradero desconocido ${ }^{10}$, medían 7,5 × 14,5 palmos y debían estar terminados para

\footnotetext{
${ }^{7}$ Archivo del Reino de Valencia. Protocolos de Mauricio Segarra n. ${ }^{\circ}$ 19.205. 2 de Noviembre de 1655. Pere Salvador cobró por los tres lienzos 40 libras. La deuda quedó saldada el 24 de enero de 1656 . Archivo del Reino de Valencia. Protocolos de Mauricio Segarra n..$^{\circ} 7.533$.

${ }^{8}$ R. García Mahíques, «Vicente Salvador Gómez y la iconografía de San Ignacio de Loyola en la Casa Profesa de Valen cia». Boletín del Museo e Instituto Camón Aznar, LXII, 1996, pp. 57-79.

${ }^{9}$ Archivo de Protocolos del Patriarca. Valencia. Protocolo de Marcel Ciprer de Paternoy, n. ${ }^{\circ} 27.592 .9$ de Diciembre de 1663 .

${ }^{10}$ Sobre el por qué, hoy en día, no se conservan los cuatro lienzos pintados por Salvador para la capilla de S. Vicente Ferrer, se puede recordar el relato al respecto de Orellana: «También los lienzos grandes que avia en la Capilla de san Vicente Ferrer (antes de que se construyera como está ahora) los quales se idearon en 1664 y el que allí está en acto de escribir es retrato de dicho Vicente Salvador, cuyos cuatro lienzos haviéndose quitado para obra dicha capilla, luego que se con-
} 
el día de San Vicente Ferrer de 1664. Los dos segundos, que todavía se conservan en el convento de Santo Domingo de Valencia, medían según el contrato $17,5 \times 21,5$ palmos y tenían que entregarse el día de Navidad de 1665. El pintor por su trabajo recibiría, de don Luis Carros, 200 libras en moneda real de Valencia. El análisis formal de los dos cuadros que se conocen, El compromiso de Caspe y La llegada milagrosa de las naves, pone en evidencia que Salvador siguió fielmente, el estilo de Espinosa en cuanto a composición, colorido y dibujo se refiere, demostrando, como su maestro, una notable capacidad para el retrato ${ }^{11}$.

Se puede pensar que nuestro pintor con 26 años, tenía cierto prestigio en Valencia, pues había recibido encargos importantes y, aunque estilísticamente estaba muy ligado a Espinosa, ya era un pintor independiente del taller de su maestro y se le exigía pintar de su propia mano. Probablemente de esta época, todavía juvenil y «espinosiana», sean el cuadro de San Gregorio Magno (Museo San Pío V) que, según Ceán y Orellana, se encontraba en la sacristía del Convento de Santo Domingo y la Muerte de la Virgen (colección privada madrileña) en la que Salvador utilizó para su realización una estampa del Cornelis Cort del mismo asunto y sobre composición de Federico Zuccaro ${ }^{12}$. En 1668, preparó el dibujó para la portada del libro, $L a$ Montesa Ilustrada de Hipólito Samper, que fue grabado por el madrileño Pedro de Villafranca. En esta obra, como advirtió Pérez Sánchez ${ }^{13}$, el valenciano repite, en los santos que adoran a la Virgen, los modelos rotundos y pesados de Espinosa mientras que en el San Jorge y el Dragón, que aparece en el centro de la imagen, la composición se muestra ya con un mayor dinamismo, de pleno barroco, que indica el conocimiento de otras fuentes formales, más allá de las enseñanzas de su maestro y que, tal vez, pudo haber estudiado en otra ciudad.

No es descabellado imaginar que el joven Salvador, deseoso de aprender y movido por su curiosidad, quisiera abandonar Valencia para poder viajar a Madrid y, quizás también, a Italia. En la corte madrileña estaba la colección real, en aquel momento la más importante de Occidente, vivía gran parte de la nobleza protectora de las artes y los artistas de mayor prestigio al servicio del Rey. En este sentido, el hecho de que Salvador y Villafranca colaboraran en la Montesa de Samper es un indicio claro de su posible estancia en Madrid. Esta hipótesis se refuerza claramente si se señalan las relaciones de mecenazgo que nuestro pintor mantuvo con algunas familias de la aristocracia residente en la Corte. Vale la pena recordar, al respecto, su dibujo de San José con el Niño en su taller que se conserva en el Museo de la Universidad de Michigan, en el que aparece un escudo con una inscripción: «Aquí làs armas del ex. ${ }^{\circ} \mathrm{Sr}$. Duque de Arcos m. S. año 1674 f.» ${ }^{14}$. La expresión «mi señor» es claramente reveladora del patronazgo existente entre Arcos y el artista, quien probablemente preparó el dibujo como boceto para un lienzo o para luego grabarlo, como había hecho en la Montesa Ilustrada.

Los Duques de Arcos protectores de las artes, y posiblemente mecenas de Vicente Salvador, poseyeron un significativo patrimonio artístico. Don Manuel Ponce de León para quien, probablemente, el valenciano preparó el citado dibujo, tenía en 1693 una colección de unas 100

cluyó como existe en el año 1781 , se volvieron a poner en las paredes de dicha capilla dos de los referidos y los otros dos se hallan en las paredes de otra capilla del claustro». Orellana, Biografía Pictórica Valentina, ed. de Xavier de Salas, Valencia 1967, p. 269. Es posible que estos dos lienzos: La aparición de la hermana del santo cuando éste celebraba misa en la Iglesia de Predicadores y La muerte de San Vicente Ferrer, situados en una capilla del claustro, pudieran haber desaparecido debido al deterioro provocado por las inclemencias del tiempo.

"' Desde Orellana se ha querido ver en una de las figuras representadas en la Llegada de la naves el autorretrato del pintor, e incluso se ha intentado là identificación de las otros personajes en el lienzo. Por otro lado, recuérdese la existencia de un dibujo preparatorio para el Compromiso de Caspe que se conserva en el gabinete de dibujos de los Uffizi en Florencia. Para un estudio en detalle de estas dos obras véase, A. Pérez Sánchez, «Obra cit.» Boletín del Museo del Prado, 2, 1980, p. 72

12 B. Navarrete, «Obra cit.», Ars Longa, 1996, p. 174

${ }^{1.3}$ A. Pérez Sánchez, «Obra cit.», Boletín del Museo del Prado, 2, 1980, p. 74.

${ }^{14}$ A. Espinós, Dibujos valencianos del siglo xvi, Catálogo de la exposición. Museo San Pío V. Valencia 1994, pp. $153-187$. 
obras, que incluía piezas de pintores españoles, italianos y flamencos de diversa importancia ${ }^{15}$. Su hijo, don Joaquín Ponce de León, en los años que siguieron a la muerte de don Manuel, incrementó significativamente la galería que había heredado. En 1733, a su muerte, dejaba a doña Ana Spínola de la Cerda, su viuda, un grupo pictórico de mas de 400 obras ${ }^{16}$ de asunto principalmente profano, con una extraordinaria abundancia de cuadros mitológicos. Entre las piezas que formaban esta colección se encontraban diferentes obras de Velázquez — de las que destaca un boceto para las «Meninas»-Alonso Cano, Murillo, el Greco, Mazo, Carreño, Labrador, Rafael, Teatino, Lanfranco, Vaccaro, Tiziano, Tintoretto, Solimena, Correggio... Asimismo, poseía diversas esculturas de carácter mitológico, otras del maestro italiano Juan Bautista Morelli, amigo de Velázquez, y diversas decoraciones — «mutaciones»— pintadas para las representaciones de teatro.

Un dibujo publicado en los últimos años por la Dra. Adela Espinós, vuelve a poner de relieve la relación del pintor con la nobleza madrileña. Se trata de un boceto en el que se representa el abrazo de San Joaquín y Santa Ana ante la puerta dorada y en el que se observa la siguiente leyenda: «Diseño del $2 .^{\circ}$ quadro del Ex.mo Sr. Conde de Paredes el qual según su carta, a de contenerlo hecho, menos que en heste caso...». Don Tomás de la Cerda Manrique de Lara, Conde de Paredes y Marqués de la Laguna tenía en 1692 una pequeña colección de pinturas ca. 70-, cuyo estudio es muy interesante al ponerlo relación con el citado boceto ${ }^{17}$. En la galería del Conde se encontraban, además de 4 obras de Lucas Jordán, una serie de lienzos tasados altamente y de temas del Antiguo y Nuevo Testamento: La Adoración de los Reyes, El Templo de Salomón, La Reina de Saba y El Rey Salomón, Sansón en la ruina del templo y «dos pinturas iguales de las puertas de doradas de santa Ana», entre otros. Es factible imaginar que estos dos últimos cuadros fueran, teniendo en cuenta la leyenda citada, los realizados por Salvador para el Duque, tasados por el pintor Domingo Martínez en 700 reales cada uno y de los que, por el momento, sólo se conserva el dibujo preparatorio para el segundo.

Este dibujo refleja, en nuestra opinión, un conocimiento del arte italiano y quizá pueda ser útil para apoyar la hipótesis de un posible viaje, por los menos, a Roma. El encuentro ante la Puerta Dorada es de composición plenamente clásica, en la que los protagonistas, en conversación reposada, se sitúan en el centro de la escena. La acción principal queda enmarcada por diversas alturas de arcos de medio punto, apoyados en órdenes dóricos que presentan, en el intradós del arco sobre el dintel, decoraciones de hexágonos y medios rombos y, en el entablamento, ornamentos de bucráneos y triglifos. Esta composición, de corte tan clásico, puede tener un referente lejano en la misma «Escuela de Atenas» de Rafael, obra admiradísima, en la que el pintor de Urbino utilizó una composición centrada por una bóveda de medio punto decorada por elementos hexagonales y romboidales, y en donde el espíritu de reposo se observa también en los dos filósofos que parecen conversar en el centro de la escena ${ }^{18}$.

Asimismo, Salvador introduce en su dibujo otros componentes, esta vez, de naturaleza barroca. El ángel que se precipita con la filacteria es típicamente una forma italiana del siglo XVII y algunos elementos arquitectónicos nos permiten recordar decoraciones borrominescas

\footnotetext{
${ }_{15}^{15}$ M Burke \& P. Cherry, Collections of paintings in Madrid 1601-1755, Paul Getty trust 1997, vol. 1, pp. 963 - 971.

${ }^{16}$ Archivo Histórico de Protocolos, n. 14929 ff. 90v.-125r. Este inventario es parte integrante de la tesis doctoral de Salvador Salort, Coleccionismo privado de pinturas en el Madrid de los siglos xvir y xvil, en fase de finalización.

17 Tasación post-mortem de las pinturas del Marqués. Archivo Histórico de Protocolos de Madrid, protocolo n. ${ }^{\circ} 9887$, folios 898-97. Este inventario es parte integrante de la tesis doctoral de Salvador Salort, Coleccionismo privado de pinturas en el Madrid de los siglos xv"l y xvm, en fase de finalización. La heredera de don Tomás fue su mujer, Doña M. ${ }^{a}$ Luisa Manrique y Gonzága, probablemente hija de Vespasiano Gonzaga, gentilhombre de Carlos II, y de María Inés Manrique, que a su vez poseían una importante colección y claros vínculos con Valencia, ya que D. Vespasiano fue Virrey de Valencia. El inventario de esta colección se publicó en: M. Burke \& P. Cherry, Obra cit. Getty Trust, vol. I, 1997, pp. 694-699.

is No hay que olvidar que las estancias de Rafael fueron grabadas por Raimondi y que Salvador pudo haber conocido esta estampa, ya que entre los bienes a la muerte del pintor se inventarían un gran número de grabados.
} 
que en España eran aún poco conocidas. Nos referimos a los capiteles en forma de cabeza de ángel con alas, emplazados sobre las pilastras que sujetan el arco de la puerta principal, en cuyas enjutas, a su vez, se vuelven a repetir decoraciones angélicas que extienden sus alas para cubrir todo este espacio arquitectónico. Igualmente, se puede relacionar con la obra de Borromini las decoraciones de relieves rectangulares asociadas a otras circulares con guirnaldas de hojas tupidas, tal y como hiciera, de forma parecida, el italiano en San Giovanni in Laterano de Roma. Finalmente, se advierte un claro cuidado y preocupación por la composición y decoración arquitectónica constatada, no solamente por la propia elaboración del dibujo sino también, por la leyenda que en esta aparece: «... A la arquitectura la qual no dicen los historiadores de que horden fuese y asi ha se elegido la dórica...».

El interés de nuestro maestro por las representaciones arquitectónicas lo puso de manifiesto Orellana: «fue muy perspectivo, de forma que en cualquier pintura luego se inclinaba a figurar edificios y fábricas de una admirable perspectiva, con que descubría su particular estudio en la arquitectura». Este hecho unido a su gusto por lo italiano ya habían sido advertidos por Pérez Sánchez en los lienzos de la Liberación de San Pedro ${ }^{19}$ (Museo de Franz Mayer, México) y la Expulsión de los mercaderes del templo (Museo del Prado). Dos obras que están concebidas como cuadros de perspectivas, a la italiana, tal y como hicieran los romanos Viviano Codazzi o Michel Angelo Cerquozzi a la hora de representar los elementos arquitectónicos de este tipo de lienzos y los napolitanos Mico Spadaro y Salvatore Rosa o el genovés Valerio Castello por lo que respecta a los grupos figurativos de los mismos.

Como vamos viendo, todo lo hasta ahora apuntando, induce a pensar en un posible viaje de nuestro pintor a Italia. Esta hipótesis se puede reforzar al poner de relieve las buenas relaciōnes artísticas que existieron, durante el tercer tercio del siglo xvII, entre Valencia y la ciudad papal, tal y como se demuestra en la documentación que se conserva en los principales archivos romanos. De hecho, Roma contaba en el último tercio del siglo con la presencia de muchos valencianos como, por ejemplo, la de don Juan Martínez de la Raga, agente del Colegio del Corpus Christi de Valencia en la urbe. Éste en el año 1678 encargó al pintor italiano Francisco de Rossa 17 cuadros, retratos, todos ellos, del patriarca Ribera que se entregaron, posteriormente, a algunos «Ministros» ${ }^{20}$. Igualmente, no hay que olvidar que, en aquel tiempo, el pintor español más famoso residente en la ciudad papal era el valenciano Vicente Giner que, como bien se sabe, intentó fundar en 1680 una academia de pintores españoles ${ }^{21}$. Giner vivía en Roma, por lo menos, desde $1671^{22}$ y debió ser conocido entre los españoles asentados en la ciudad, como pintor de perspectivas. Así pues, don Miguel de Zetina, canónigo de la Santa Iglesia Metropolitana de Zaragoza y residente en Roma, tenía en su pequeña colección de pinturas, cuatro perspectivas, dos de mano ordinaria y las otras dos «de mano de Don Vi-

\footnotetext{
19 Vale la pena recordar que, para la ejecución de esta obra, Salvador se apoyó, por lo que a la composición arquitectónica se refiere, en una estampa de Agostino Carracci que reproducía el célebre cuadro de Federico Barocci, Eneas salvando a Anquises del inciendio de Troya, actualmente, en la Galería Borghese de Roma, B. Navarrete, "Obra Cit», Ars Longa, n. 6, 1996, pp. 135-40. Asimismo, el citado grabado de A. Carracci, se puede poner en relación, por idénticas razones, con el dibujo de Salvador, La liberación de San Pedro, hoy en día, en el Museo de Bellas Artes de Valencia. Cfr. Angulo y Pérez Sánchez, Obra cit, London 1988, vol. IV, pp. 77 y dibujo n. ${ }^{\circ} 395$.

${ }^{20}$ Archivio Capitolino de Roma. Archivio Urbano, sezione 1.", protocolo n. ${ }^{\circ} 644.25$ de junio de 1678 . Firmaban como testigos los valencianos Gregorio Brotons y Vicente Aguilar, residentes en Roma. Para Vicente Giner y en relación a estos documentos véase: Ángel Aterido Fernández, «De Castellón a Roma: El canónigo Vicente Giner (ca. 1636-1681)», en A.E.A., 294, 2001, pp. 179-183.

${ }^{21}$ Archivio Capitolino de Roma. Archivio Urbano, sezione I. ${ }^{a}$, protocolo n. ${ }^{\circ} 642.28$ de Julio de 1680 . La copia de este documento se encontraba en España y fue publicada en el diccionario de Viñaza. Vicente Giner aparece como virtuoso al Panteón en la lista entre 1600 y 1700 donde también figura Velázquez. Véase Statuto della insigne atistica congregazione pontificia dei virtuosi al Pantheon, Roma, 1861, p. 61.

22 Archivio Capitolino de Roma. Archivio Urbano, sezione 1. ${ }^{a}$, protocolo n. ${ }^{\circ} 632.22$ de Abril 1671, Documento por el que Giner compra algunas estampas. Para Giner ver el reciente artículo de Aterido, loc. cit. nota 20.
} 
cente Giner valenciano sin corniças de a siete y cinco» ${ }^{23}$. En relación con todo ello, no nos parece arriesgado el pensar que Salvador fuera conocedor, y quizás también partícipe, de este ambiente valenciano en Roma. Ambiente protagonizado por Giner que igual que aquél fue pintor de arquitecturas y director de una Academia de pintores, aunque esta fuera non-nata.

Si alguna vez se produjo el viaje a Italia, Salvador lo tuvo que haber realizado antes de diciembre de 1668 o después de 1675 ya que, durante el tiempo comprendido entre estas dos fechas, está documentado en Valencia. A este respecto, la mayor parte de los textos notariales que hemos encontrádo, refieren noticias sobre sus deudas y préstamos con otros individuos, de los que cabe mencionar al escultor Tomás Sanchiz, y que por su interés, fundamentalmente anecdótico y erudito, no estudiamos detalladamente ${ }^{24}$. En 1669, Vicente Salvador vivía en Valencia en el «vico de les Barques» dentro de la parroquia de San Andrés ${ }^{25}$. Un año más tarde, según Orellana, firmó un dibujo llamándose Director o Académico Mayor de Santo Domingo ${ }^{26}$, institución descrita por el maestro García Hidalgo como: «Aula muy capaz en donde los pintores hacen sus academias, y allí asistíamos Castellanos y Valencianos con algunos caballeros y eclesiásticos que por afición concurrían a dibuxar, ver y oir» ${ }^{27}$. Es factible imaginar que esta Academia tuvo que haberla conocido Giner, quien 10 años más tarde, como hemos apuntado, trataría en Italia de fundar otra de españoles en Roma, emulando la que tenían los franceses y otras «naciones» en la ciudad de los papas y, quizás, sin olvidar el ejemplo de la de su «patria chica».

Si la noticia de Orellana es correcta, Salvador con 33 años, ya maduro y formado, era Académico Mayor del «Aula» de Santo Domingo, circunstancia que le convertía, desaparecido Espinosa en 1667, en el pintor de mayor prestigio en la ciudad. De esta época tenemos noticia de algunos de los encargos que recibió como, por ejemplo, el de uno de sus notarios, Marcelo Ciprer de Paternoy, quien «por diferentes pinturas» le pagó en 1670, 35 libras ${ }^{28}$. De este documento, en el que no se describen cómo eran las obras, vale la pena señalar a uno de los testigos citados: Miguel Segura, asimismo pintor y seguramente amigo de Salvador, ya que éste le vuelve a citar como tal en otros textos notariales ${ }^{29}$.

El prestigio profesional que debió tener durante aquellos años se puede observar en los, ya apuntados, vínculos de mecenazgo con la nobleza madrieña e, igualmente, en las relaciones laborales que mantuvo con la aristocracia valenciana. Por citar algún ejemplo, los duques de Segorbe le encargaron en 1671 dos cuadros; uno de San Vicente Ferrer y el otro de San Pascual Bailón ${ }^{30}$. Además, como testimonio de su fama y crédito, podemos señalar que los duques le pagaron 300 reales por cada lienzo mientras que a otro pintor, Vicente Ayerve, le dieron solamente 80 reales por un cuadro del Buen Pastor, que le habían encargado por las mismas fechas ${ }^{31}$.

\footnotetext{
${ }^{23}$ Archivio Capitolino de Roma. Archivio Urbano, sezione I. ${ }^{2}$, protocolo n. ${ }^{\circ} 643.23$ de octubre de 1681.

${ }^{24}$ Por orden cronológico, los documentos, siempre del Archivo del Reino de Valencia, son los siguientes: Protocolos de Francisco Sebil, n. 45 16, 19 de Diciembre 1668, V. Salvador vende una deuda de 48 libras a Miguel Locar, siendo testigos los pintores Gaspar de la Huerta y Miguel Vilar; n. ${ }^{\circ} 4517,16$ de Abril de 1669, se pagaron a V. Salvador, en aquel momento ausente de la ciudad, 72 libras por el alquiler de casa que tenía en la calle Carniceros; n. 4517,9 de enero de 1670, V. Salvador paga a José Bosch 24 libras «a cuenta y resto total de vuestra oficina»; n. ${ }^{\circ} 4517,22$ de febrero de 1670 , V. Salvador contrae una deuda con José Vidal de 80 libras, siendo uno de los testigos el pintor Miguel Segura. La deuda se saldó el 23 de septiembre; n. ${ }^{\circ} 4517,4$ de marzo de 1670, V. Salvador contrae una deuda con el escultor Tomás Sanchiz de 30 sueldos, siendo uno de los testigos el pintor Miguel Segura. La deuda se saldó el 20 de marzo de 1670, siendo testigos el escultor Francisco Salvatierra y el carpintero Antonio Adell.

${ }^{25}$ B. Navarrete, «Obra cit.», Ars Longa, 1996, p. 135.

${ }^{26}$ Orellana, Obra cit. Edición de Xavier de Salas, Valencia 1967, pág, 271. El dibujo representaba a Sansón y Dalila y estaba fechado el 1 de febrero del citado año.

${ }^{27}$ J. García Hidalgo, Principios para estudiar el nobilísimo y Real arte de la pintura, ed. del Instituto de España 1965 , folio 7 vuelto.

${ }^{28}$ Archivo del Reino de Valencia. Protocolo de Francisco Sebil n. ${ }^{\circ} 4517.16$ de mayo de 1670.

${ }^{29}$ Véase nota $n .^{\circ} 24$.

${ }^{30}$ A.P.P.V. Protocolo de Marcel Ciprer de Paternoy, n. ${ }^{\circ} 27.595 .3$ de abril de 1671.

${ }^{31}$ A.P.P.V. Protocolo de Marcel Ciprer de Paternoy, n. ${ }^{\circ} 27.595 .23$ de junio 1671.
} 
Pensamos que Vicente Salvador, en vista de los encargos que recibía debía tener una economía suficientemente saneada. Esta economía se reforzó sin duda cuando, ya mayor, con 33 años, contrajo matrimonio con Francisca Agramunt, hija de un mercader, que aportó como dote al matrimonio 300 libras por valor de diversas joyas de oro y plata, ropas etc. y 150 libras más por ser doncella virgen ${ }^{32}$. Durante los años que siguieron a su matrimonio, no hemos encontrado pruebas de otras actividades pictóricas a parte de la realización, en 1674, de la Cartilla y fundamentales reglas de la pintura, para que fuera utilizada en la Academia de Santo Domingo. De todos modos, esta ausencia de documentos referentes a contratos no es significativa de un momento de baja producción pictórica ya que, en 1675, entraba como aprendiz en su taller un joven llamado Francisco Hernández ${ }^{33}$, hecho que indica la necesidad de que alguien le asistiera en el trabajo.

Desde 1675 hasta 1678, no hemos encontrado ninguna referencia documental de Salvador en Valencia, circunstancia que parece indicar su ausencia de la ciudad. Tal vez en ese periodo, y en base a los cambios estilísticos ya analizados en algunas de sus obras, el valenciano realizara un viaje de aprendizaje a Madrid o Italia, viaje que, por el momento, no se puede demostrar objetivamente. El 3 de abril de 1678, Vicente Salvador y Gómez, pintor y familiar del Santo Oficio, declaraba estar enfermo en la cama de una «greu malaltia corporal» de la que se sentía morir. Por esta razón redactaba su testamento ante el escribano Vicente Tost, nombrando «marmessors» a Pere Salvador, «pintor mon pare», y a Luciano Salvador, «tambe pintor mon germa» ${ }^{34}$. De su testamento vale la pena recordar que quiso ser enterrado en la iglesia de S. Andrés de Valencia, que dejó la gran mayoría de sus bienes a sus hijas Vicenta y Bernarda y a su mujer Francisca y algunas pinturas a diversos amigos, muchos de ellos, doctores en medicina, que le habían asistido gratuitamente en su postrera enfermedad ${ }^{35}$.

Sabemos que el pintor murió 4 días después de testar y que, el 11 de abril, se hizo inventario de sus bienes en la casa donde vivía, sita en la parroquia de San Andrés. En el documento se describen, principalmente, su biblioteca y su colección de pinturas. De esta última se deben citar, un cuadro de paisaje de mano de Ribalta, otro del mismo género originario de Italia y un grupo de pinturas sin atribución alguna y de variada temática. Estos lienzos «anónimos» debieron ser en su mayoría pintados por Salvador y, en nuestra opinión, son indicativos de que éste, no sólo fue un pintor de escenas religiosas y perspectivas sino también, fue retratista, pintor de animales, flores y paisajes. Pensamos que esta hipótesis se puede asimismo sustentar al observar que el valenciano, en su muy bien fornida biblioteca, tenía más de trescientas grabados de paisajes, un volumen de la Historias naturales de peces y animales de mar y de tierra de Juan Justonio con estampas finas, la de Cayo Plinio, cuyos modelos pudo haber estudiado y utilizado - como en otras ocasiones- para sus obras ${ }^{36}$.

\footnotetext{
32 B. Navarrete, «Obra cit.», Ars Longa, 1996, p. 136.

${ }^{33}$ A.P.P.V. Protocolo de Miguel Ximeno, n. ${ }^{\circ} 10.356,23$ de junio de 1675

${ }^{34}$ A.P.P.V. Protocolo de Vicente Tost n. ${ }^{\circ} 17.395,3$ de abril de 1678.

${ }^{35}$ Idem. Al Dr. Lluis Chiva «un quadro chiquet hon esta pintat una image de nostra señora que te indulgencia», al Dr. Joan Batiste Gil «una lamina del Santo Cristo», al Dr. Francisco Leonart «un quadro de la Asumpcio de Nostra Señora». Asimismo dejó «un quadro del Bateig de Sant Joan Batiste a mosen Alejandro Gomes, probablemente familiar suyo, «un quadro del retrato del Padre Dr. Antoni Sarrio» al vicario de la Iglesia de San Lorenzo Dr. Jaume Gil de Castellvi y a Mosen Vicent Grau «un retrato del pare Vicent Orient». Todas estas obras fueron, posiblemente, de mano de V. Salvador.

${ }^{36}$ Las pinturas descritas en el inventario de V. Salvador son las siguientes: "Quatre quadres grans sens guarnicio pintats en aquelis ço es en los dos diferents generos de pardals y les altres dos ab uns bous y gozos, un quadro pintat en aquell una borrasca de mar, un quadro chiquet pintat la imatge de Nostra Señora, un quadro chiquet con una imabge de Nostra Sra. en lo niño en los brasos sens guarnisio, un quadro del Nacimiento en borro, dos quadros Ntra. Sra. de la Soledad y La Purisima sens guarnisio, un quadro pintat en aquell un circulo de flors, un Niño Jesus en borro que es copia del de Doña Isabel Trilles, un quadro michanser con guarnisio negra de la Asumpcio de Nuestra Sra., dos quadros retrats de Marti Almansa y su mullier, un quadro chíquet ab la imatge de Nra. Sra. dels Desamparats, un quadro molt chiquet ab lo Niño Jesus, Sent Joan y un borreguet, un pais gran pintat la civtat de Murcia sens guarnicio, un quadro pintat lo arcangel St. Miquel en
} 
En cuanto a la biblioteca hay que señalar que su importancia y su riqueza se deben, en gran parte, a la adquisición que en 1673 hizo Salvador de «tosts los modelos, papers, estampes et debuxos de diferents personajes y sancts caixes y bauls del Quondam D. Alonso Cano pintor de la Magestad del Rey Phelip Quart tot los qual limbiá lo dit Don Alonso Cano de la ciutat de Granada a la casa hospici de la cartuxa que esta situada en la presente ciudad de Valencia» ${ }^{37}$. Como es sabido, en 1644, Cano fue a Valencia con muchas de sus pertenencias y, probablemente, con la intención de ingresar en la Cartuja de Portaceli, después del misterioso asesinato de su mujer en Madrid ${ }^{38}$. Años más tarde, el propio Cano en su testamento declaraba que en la «ciudad de Valencia tengo algunos libros de arquitectura, estampas y algunos moldes dentro de unos cofres... Que está y lo dejé en la ospeeria en el Convento de la Cartuja de dicha ciudad que todo está en unos cofres y cajas...» ${ }^{39}$.

Los moldes que Cano afirma haber dejado en Valencia y que luego Salvador compró, deben ser los que aparecen citados en el inventario post-mortem que estudiamos: «treinta y sis models ço es caps, peus y mans de algeps» ${ }^{40}$. Asimismo y tal y como se desprende del documento ${ }^{41}$, las piezas estaban guardadas en un aposento, lugar en el que, seguramente, las estudiaba y dibujaba con el objeto de ilustrar su cartilla. Por lo que respecta a las estampas, tenía un gran número de ellas, unas veces reunidas en volúmenes y, otras, intercaladas entre los textos de los numerosos libros que poseía. Como se ha demostrado, se servía de aquéllas para la composición de algunos de sus cuadros y en este sentido, es seguro que conoció y manejó estampas de Cornelis Cort, Agostino Carracci, Raffaelo Schiaminossi, Cornelis y Theodor Galle, Adrian Collaert, Karel Mallery o Durero ${ }^{42}$.

Por lo que concierne a los libros que formaban la biblioteca, es muy difícil saber con precisión cuáles eran los volúmenes que pertenecían a Salvador, antes de la compra de 1673, y cuáles eran los que Cano había dejado en la Cartuja en septiembre de 1645. Como es lógico pensar los libros impresos en ediciones valencianas, los que aparecen repetidos en el inventario, la Montesa Ilustrada de Samper o los publicados después de septiembre de 1645, momen-

borro, una quadro pintat del Bon Pastor en borro, un paiset de Italia ab un peñasco, altre pais píntat un pont en aquell, una piaset de ma de Ribalta, un paiset pintat una ruina, un quadre en borro pintat $\mathrm{N} .^{\circ}$. Sr y la mare de Deu, un quadre en borro pintat lo bon pastor, un quadre en borro pintat Sta. Gertrudis, un quadre en borro pintat la fugida a Egipto, un quadre en borro pintat de estofat, un quadro del Rey Davit ab guarnisio daurada, dos quadrets chiquets de prespectiva, altre quadret pintat de Sent gregori, dos quadros míchancers en borro, un altre quadret pintat de la Adoracio y el naximent en borro, quatre quadres grans sens guarnisio, lo hu de la Historia de Judic, lo altre de la Reyna Ester, lo altre del Glorios Sent Sebastia y lo altre de los tres Reyes, una tauleta pintada en aquella les armes de la lnquisicio, quatre quadrets pintats en una vena de pam de liens ço es S. Luis Beltran, S. Gerony, Sta Theresa de Jesus y Sta. Monicas.

${ }^{37}$ Navarrete Prieto, B., «Obra cit», Ars Longa, 6, 1996, p. 136.

${ }^{38}$ H.E. Wethey, Alonso Cano. Painter; Sculptor, Architect, Princeton, 1955, ed Española, 1983, p. 213.

${ }^{39}$ Idem.

40 Treinta y seis modelos de cabezas, pies y manos en yeso.

${ }^{41}$ En una de las entradas se declara lo siguiente: «Per quant Marcos Gisbert quant sen ana a Sardeña me dexa y encomana una caxa de papers ab cola de una dotsena de modelos que esta huy en lo aposento dels modelos vuil que apres mort mía sia entregada aixi dita caixa, papers, modelos com una tauleta y un caixonet que esta en la cuina a Joan Batiste Luna pera que aquell los guarde y eis entregue a son temps a qui sap se han de entregar».

${ }^{42}$ Las entradas del inventario en las que se citan estampas son las siguientes: «cent vint estampes de papers de paisos michancers, doscentes quaranta estampas de paper de diferents paisets chiquets aixi de personaches com de animals terrestres y bolatiles, trenta estampes fines de paper de diferents Sants y Santes usadas, la vida de Sant Agusti en vint y huit estampes fines usades, doscentas setanta estampes entre grans y $y_{1}$ chiquets molt usades y rompudes de diferents histories y Sants y Santes, la vida de Christo en once estampes de paper comunes, un libro con setenta estampas y dibujos (en $8 .^{\circ}$ ), Emblemas de Covarrubias con estampas (en 4..$^{\circ}$ ), Imagenes de los dioses de los antiguos en italiano con estampas, Las empresas de Ruceli en estampas, Triumphus Jesuchristi con estampas, dos libros de estampas de la Pasion, Los discursos de los antiguos romanos con estampas, Historias naturales de peces y animales de mar y tierra de Juan Justonio con estampas finas, Metamorfosis de Ovidio con estampas, Imagenes y edificios de la Tierra Santa, Teatro de figuras matemáticas con 60 estampas, Empresas de Fabricio con estampas, Empresas políticas de Saavedra con estampas finas, Honras de Felipe IV en Madrit con estampas" y otros muchos libros incluidos en la biblioteca del pintor que sabemos, hoy en día, que venían ilustrados con grabados, aunque en el inventario no se declare. 
to en el que Cano deja Valencia, pertenecían con mucha probabilidad, a Salvador. Quizás a éstos se puedan añadir los de autores de origen valenciano, aunque este no sea un criterio que nos otorgue plena certeza sobre la cuestión. Por su parte, Cano declaraba en el testamento que había dejado en Valencia solamente «algunos libros de arquitectura», tal vez porque, después de haber pasado un largo tiempo desde su estancia en la Cartuja, únicamente recordaba el asunto de aquellos volúmenes que le eran más queridos, por su valor e importancia. Efectivamente, entre las posesiones del valenciano encontramos una abundancia, poco frecuente en las bibliotecas de artistas españoles del siglo Xvir, de tratados de arquitectura de los que vale la pena recordar el de Vitruvio, Serlio, Cattaneo, Rusconi, Philibert de l'Orme y Viola, Palladio, Labacco, Alberti, Fray Lorenzo de San Nicolás, Arfé, Sagredo, además de una Regula Generale de la Arquitectura anónima y tres ediciones del Viñola, dos en español — suponemos la de Patricio Cajés-y una en italiano ${ }^{43}$.

Orellana ya advirtió el gusto por la arquitectura de nuestro pintor, que hemos podido comprobar al referir algunos de los títulos de su biblioteca, al estudiar el dibujo para el Marqués de Paredes y al recordar el lienzo del Museo del Prado. Asociado a este gusto afluye el interés por las matemáticas, la geometría y la perspectiva que son sin duda, herramientas necesarias a la hora de construir una composición pictórica y por las que el valenciano tenía una inclinación notable. En este sentido, su biblioteca era de gran riqueza, ya que poseía diversos libros de Euclides, los tratados de perspectiva de Viñola, Sirigati y Barbaro, el Teatro de los instrumentos y figuras matemáticas de Besson, el Matematimacorum de Antonio Machinilo, los Instrumentos de Geometría de Barozzi, el Matematicarum de Ciruelo, la Aritmética de Ventallol, la de Cortés y la de Zaragoza, Los números y medidas de Tartaglia, Cosimo Bartoli, Del modo de misurare, entre otros.

Siempre en unión con las artes plásticas la biblioteca no nos deja de sorprender, porque en ella se pueden descubrir otros títulos y autores de mucha importancia como, por ejemplo, las Vidas de Vasari, la Simetría de Durero, los Dicursos de Butrón, la Noticia General de Gutiérrez de los Ríos, el tratado de pintura de Carducho, el de Armenini, el de J. Paolo Tommaso y otro anónimo publicado en Roma. Asimismo, tenía algunos libros de emblemática, muy útiles para su profesión, como los Emblemas Morales de Covarrubias, los de Alciato, la Emblemata de Solorzano, las Empresas de Ruscelli, Capaccio o las de Saavedra, todos ellos ilustrados con preciosas estampas.

Salvador era «Familiar del Santo Oficio de la Inquisición y Censor de las Pinturas en su decencia y culto por el dicho Tribunal», en su casa tenía un escudo con las armas de la citada institución y fue enterrado con los hábitos de la Orden Tercera, tal y como él quiso. Este oficio y devoción religiosa se puede ver reflejada, a su vez, en la variedad de textos de naturaleza devota que se describen en el inventario, y que denotan un interés en llevar a cabo correctamente su labor de «veedor», así como una cierta cultura teológica. Entre sus libros, sobresalen las obras de Juan Bolando, Fray Vicente Justiniano, Francisco Romulo Berlamino, San Ignacio de Loyola, San Gregorio, Hermann Bussebaum, el padre Falconi, Enrique de Villalobos, Fray Luis de Granada, San Agustín, Andrés de Vega, etcétera. Igualmente, se refieren una Biblia de Lyon, un catecismo, diversas vidas de santos, un Tratado de Concepción, un Ideal del Predicador y tres Flors Sanctorum - el de Villegas, el de Ribadeneyra y otro en italiano-, que le servirían como, más adelante escribiría Palomino, «para tener plenísima noticia» de las historias sacras que tuviera que representar en el lienzo. De gran interés es la presencia de una «Historia de San Diego» que bien pudiera ser la obra de Gabriel de Mata, Vida, muerte y milagros de San Diego de Alcalá, Madrid, 1598, obra fundamental para Alonso Cano en la Capilla

${ }^{43}$ Para un estudio exhaustivo de la biblioteca véase el documento al final del presente estudio. 
de San Diego del convento franciscano de Santa María de Jesús de Alcalá de Henares, donde realizó un dibujo preparatorio con escenas de San Diego para el retablo mayor.

Su inclinación por lo sacro no bloqueaba, de ningún modo, su curiosidad por lo profano. Aunque de ello no tenemos constancia a través de su pintura, sí que se conservan algunos dibujos de desnudo que pueden indicar un conocimiento cercano de la mitología clásica. Su biblioteca, en este sentido, es reveladora pues en ella descubrimos dos ediciones de las Metamorfosis de Ovidio - una con estampas - y otro volumen titulado: Imágenes de los Dioses de los antiguos - también con grabados - que probablemente se refiera a la obra de Carlos Cartari, poeta italiano del siglo xvi: Le Imagini degli antichi Dei.... Cercano al gusto por la lectura de este tipo de textos está la inclinación por la literatura, tanto de autores antiguos como modernos que, en el caso de nuestro pintor, ocupaban un gran espacio en los estantes de su librería. De ellos cabe mencionar algunas obras del poeta satírico italiano Teófilo Folengo, también conocido como Merlini Cocali, las Rimas de Bocángel, el Epíteto y phocilides de Quevedo, el Arte poética de Rengifo, el Eustorgio y Clorilene de Suárez y Mendoza, las dos partes del Quijote - de la ya preciada edición de Bruselas-, el Séneca impugnado de Núñez de Castro, el Orlando de Ariosto, los Oficios de Cicerón, los Proverbios de Séneca, el Catón, las Trescientas, el Cortesano de Boscán, la Divina Comedia, las Luisadas, la Jerusalem de Tasso y la de Lope, las Coplas de Manrique, varias obras de Valdivieso, un volumen titulado Sol de Academias o Academia de Soles, entre otros.

A su preocupación por la lectura se unían la de la comprensión afinada de los textos y la de conocer bien el arte de escribir, la de la sintaxis. De ello es testimonio la propiedad de varias gramáticas (francesa, española, griega), del Vocabularium de Nebrija, del arte de Escribir de Casanova y del volumen dedicado al Estilo de escribir cartas de Juan de Leras. Todo ello le permitió, como ya se ha apuntado, el escribir su Cartilla con una correcta sintaxis castellana y una letra cuidadosa y bien dibujada ${ }^{44}$. Complementaba muy bien su gusto por las letras el interés por el conocimiento de la política, la historia de las civilizaciones, la de España y la de sus territorios allende. Encontramos entre sus volúmenes, La Razón de Estado de Botero, el Sueño Político de Fonseca, los Consejos políticos de Juan Enríquez, las Máximas políticas de Garau, las Advertencias a Reyes y Príncipes de Filantes, De Bello Judayco de Josefo, las obras de Pellicer, Los Césares de Pedro Mejía, Los Anales de Tácito, obras de Palafox, el Cronicón de Tavera, la Historia de las Indias de De las Casas, la Crónica General de España de Beuter, etcétera.

La abundancia de textos de las más diversas disciplinas científicas que se pueden entresacar de su biblioteca, le convierten en un humanista casi del estilo de los hombres del Renacimiento. Sus curiosidades abarcaban la medicina, en donde se destacan el Dioscórides de Laguna, la Antomía de Valverde -ilustrado con los dibujos, quizás de Becerra-; la Psicología con el Examen de ingenios de Huarte de San Juan; el Derecho con de Propietatibus de Martini; la Fauna con las Historias naturales de peces y animales de Juan Justonio o la Historia general de Aves y animales de Aristóteles; la Filosofía con de Consolatione philosophae de Boecio; las ciencia militar y las fortificaciones, con obras de Rojas, Carlo Theti, Lechuga, Pacheco, Narváez y Brancachio; la Arqueología con la Hieroglyphica de Bolzan o la Litologia de Olmo; la geografía y los viajes con la Geografía de Ptolomeo Alejandrino, el Compendio Geográfico de Sala o las Imágenes y edificios de Tierra Santa.

No hay que olvidar la proximidad de Valencia al mar y el interés que este pudo haber suscitado en Salvador, no sólo por la navegación sino también, por la orientación en el mismo a través de la contemplación de los astros. Por ello merece atención aparte su interesante y nu-

\footnotetext{
${ }^{4}$ A.E. Pérez Sánchez, «Obra cit.»Boletín del Museo del Prado, n. ${ }^{2} 2$, Mayo-Agosto 1980, p. 76.
} 
meroso grupo de obras relacionadas con la Cosmografía, la Astrología y la Navegación entre las que se deben mencionar: la Esfera de Zaragoza, el Tratado de la Esfera y la Chronographia de Chaves, la Esfera de Sacro Bosco, la Tabula Celsius de Beneyto, la Astrología de Campanella, la Astronomía de Ferrer, el Lunario de J. Cortés, el De situ Orbis de Pomponio Mela, el Magnitudinibus de Aristarco de Samos, el Arte de Navegar de M. Cortés, el Regimiento de Navegación de García de Céspedes, la Navegación especulativa de Nájera, etcétera.

Finalmente, vale la pena recordar el hecho de que Salvador firmara la famosa Cartilla en 1674, es decir una año más tarde de su compra de los materiales de Cano, y que además declarara el haber utilizado una extensa bibliografía para la consecución de la misma, que no especifica detalladamente pero que, hoy en día, podemos conocer gracias al inventario estudiado. Como apuntamos, los bienes del pintor pasaron a su mujer e hijas y su destino final, por el momento, lo desconocemos. En este sentido, Palomino en su vida de Cano, narra que había visto, durante su estancia en Valencia hacía 1700, en casa de «Gaspar de la Huerta (pintor de crédito en aquella ciudad), algunos modelos que dejó Cano y otras cosas de su arte» ${ }^{45}$. Esto puede indicar que De la Huerta comprara parte de los bienes de nuestro maestro en, tal vez, pública almoneda o que Salvador se los entregara, en alguna fecha que ignoramos, a de la Huerta, ya que ambos se conocieron en vida, pues éste último aparece como testigo junto a otro pintor, Miguel del Vilar, en un documento relacionado con Salvador, en $1668^{46}$.

En conclusión, se puede afirmar que, después de la muerte de Jerónimo Jacinto de Espinosa, el pintor más sobresaliente en la Valencia de la segunda mitad del siglo xviI, fue Vicente Salvador Gómez. Un artista que recibió encargos importantes desde muy joven, que fue protegido por la nobleza madrileña y valenciana y que fue nombrado Académico Mayor de Santo Domingo. Su arte evolucionó desde las pesadas y estáticas formas y composiciones «espinosianas», hacía una comprensión mucho más dinámica del arte de pintar en donde los juegos arquitectónico-perspectívicos y de diagonales y la utilización de modelos de gran vivacidad, nos permiten intuir el estudio directo de otras fuentes formales, en algunos casos borrominescas que solamente pudo haber aprendido en Italia, concretamente en Roma. En esta ciudad, en el tercer tercio del siglo xvil, la colonia valenciana era importante y en ella destacaba Vicente Giner, pintor de perspectivas y fundador de una non-nata Academia de Españoles, personaje al que, seguramente, Salvador conoció, pues las afinidades estéticas y académicas entre ambos así lo permiten pensar.

Durante su vida disfrutó de un desahogo económico notable, ya que tuvo, por lo menos, un ayudante en su taller, se casó con la «bien dotada» hija de un mercader, no se refieren deudas importantes en su testamento, recibió encargos significativos y bien remunerados y tuvo la solvencia suficiente para comprar el lote completo de los bienes dejados en Valencia por un maestro de la altura de Alonso Cano. Su biblioteca por el número, variedad de disciplinas de los textos y la calidad de los mismos y de sus grabados, es una de las más importantes habidas por un pintor español en todo el siglo xvII, superando en valor, si cabe, a la del propio Velázquez.

Su prematura muerte con tan sólo 41 años, truncó una de las carreras artísticas más interesantes del arte valenciano de la segunda mitad del siglo XVII. A este respecto, es posible pensar que, si las novedades formales que se observan en las últimas obras de Salvador se hubieran desarrollado gracias, por ejemplo, a una longevidad mayor del maestro, el panorama trasnochado de la doctrina «ribaltesca», todavía en cierta medida vigente en la Valencia de aquella época, se hubiera renovado, seguramente, hacia una estética más acorde con el cambio de los tiempos.

\footnotetext{
45 Palomino, Obra cit, Madrid 1988, t. III, p. 349.

46. A.R.V. Protocolos de Francisco Sebil, n. ${ }^{\circ} 4516,19$ de Diciembre de 1668.
} 


\section{LA BIBLIOTECA DE ALONSO CANO EN 1645: UNA HIPÓTESIS}

Partiendo de la biblioteca de Vicente Salvador Gómez, se puede reconstruir, en cierta medida la biblioteca de Alonso Cano. Para ello aplicaremos algunos criterios de selección que nos permitirán saber, por lo menos, qué libros fueron con seguridad sólo de Salvador, qué libros pudo haber dejado Cano en Valencia y qué libros pudieron haber pertenecido a cualquiera de los dos pintores.

Los criterios de selección, ya citados anteriormente, son los siguientes:

- Todos los títulos que aparecen por doble partida en el inventario, vienen a indicar que pertenecieron a ambos pintores - un volumen a cada uno-y, también, que Salvador no hizo una compra selectiva de los bienes de Cano en 1645 .

- Todos los volúmenes publicados después de septiembre de 1645, fecha en la que Cano deja Valencia, no pudieron estar entre los libros dejados por el granadino en la Cartuja y, por lo tanto, Salvador los compró entre 1646 y 1678 en otras circunstancias que ignoramos.

- Todos los libros impresos en ediciones valencianas fueron casi con seguridad de Salvador.

- Todos los libros de autores valencianos, catalanes y aragoneses fueron, probablemente, de Salvador.

Aplicando estos criterios podemos saber qué libros pertenecieron sólo a valenciano y a partir de aquí y por eliminación intentaremos reconstruir la biblioteca que Alonso Cano dejó en la Cartuja. Este sistema de selección, el único posible, no permite conocer con precisión los títulos que granadino dejó en Valencia, ya que todos los libros publicados antes de 1645, pudieron pertenecer a ambos pintores. Solamente los volúmenes cuyos títulos aparecen repetidos en el documento fueron, en uno de sus ejemplares, propiedad de Cano.

Siguiendo los criterios de selección propuestos, en el inventario iremos apuntando detrás de la entrada de cada libro lo siguiente:

- Si el volumen fue siempre propiedad de Salvador escribiremos: (Salvador). Es decir no fue nunca de Cano, ya que el libro se publicó después de septiembre de 1645 o es de un autor valenciano, catalán o aragonés, o se editó en Valencia.

- Si el volumen fue dejado por Cano en la Cartuja en 1645 escribiremos: (Cano y Salvador). Es decir se trata de uno de los libros repetidos en el inventario y, por lo tanto, perteneció a ambas bibliotecas.

- Si el volumen pudo ser comprado por Salvador en la venta de los bienes de Cano en 1673 escribiremos: (Cano - Salvador). Es decir pudo haber sido de Cano en 1645 -o no- ya que la publicación del libro es anterior a esta fecha.

- Si el volumen ofrece dificultades para la datación de su edición o incluso para su identificación escribiremos (Cano - Salvador). Es decir pudo haber sido de Cano -0 noen de 1645 .

El análisis de la biblioteca de Salvador, bajo estos criterios, permite pensar que solamente una pequeña parte de sus libros los adquirió en la compra de la Cartuja. Ello parece claro al ver que muy pocos títulos se repiten en el documento, que hay abundantes libros de publicación posterior a 1645, así como de ediciones valencianas y de autores catalanes, aragoneses y valencianos. Además, encontramos en la biblioteca numerosos libros de naturaleza religiosa, muchos de ellos publicados antes de 1645 , pero que, en nuestra opinión debieron pertenecer en su mayoría a Salvador, ya que era «Familiar del Santo Oficio de la Inquisición y Censor de las Pinturas en su decencia y culto por el dicho Tribunal». Asimismo, pensamos que los libros de gramática y arte de escribir debieron pertenecer al valenciano, que se ocupó de redactar su 
Cartilla y, por lo tanto, debió tener la inquietud de la buena expresión y del estilo. Sobre los libros de matemáticas, geometría, perspectiva, medicina, cosmografía, astrología, navegación geografía, fauna e historia es muy difícil discernir si fueron de Cano o de Salvador.

Cuestión a parte son los tratados de arquitectura y de pintura. El hecho de que Cano recordara en su testamento, que había dejado algunos de ellos en Valencia es'indicativo, por lo menos, de su número y de su importancia. Muy pocos de estos libros aparecén por doble partida en el inventario y creemos que es prácticamente imposible saber cuáles fueron con seguridad de Cano, en 1645.

\section{INVENTARIO POST - MORTEM DE VICENTE SALVADOR, PINTOR.}

A.P.P.V. Protocolos de Manuel Ximeno, n. ${ }^{\circ} 8282,9$ de julio, 1678.

En la quadra ahon vivint lo dit q..$^{\circ}$

- Un quadro del Rey Davit ab guarnisio daurada

- Itt. dos quadrets chiquets de prespectiva

- Itt. altre quadret " de Sent gregori

- Itt. dos quadros míchancers en borro

— Itt " " de la Adoracio y el naximent en borro

En un aposento despues de la libreria fonch atrobat lo seguent:

- Primo una caixa de pi molt usada ab pany y clau dins la qual fonch atrobat diferents papers enbolicats en les colors seguents:

- Itt. Dos lliures de sendres oscures

- Itt. Sis onces de azul verde

- Itt. una lliure de berdacho

- Itt. sis onces de genoli

- Itt. cinch pechinetes

- dos onces de indi

- una onsa de carmi

- huyt lliures de sombra

- cent vint estampes de papers de paisos michancers

- doscentes quaranta estampas de paper de diferents paisets chiquets aixi de personaches com de animals terrestres y bolants

- Trenta estampes fines de paper de diferents Sants y Santes usadas

- La vida de Sant Agusti en vint y huit estampes fines usades

- Doscentas setanta estampes entre grans y chiquets molt usades y rompudes de diferents histories y Sants y Santes

- Itt. la vida de Christo en once estampes de paper comunes

- Ittem en un aposento fonch atrobat tres estants de fusta de pi y en mig de aquell un almariet ab un Sant Ecce Homo en los quals estants se trobaren los llibres seguents:

- Tratado de la pintura de Roma (Cano - Salvador)

- Tratado de la pintura (Cano - Salvador)

- Dialogo de la pintura de Carducho ${ }^{47}$ (Cano - Salvador)

- Alberto Durero (Cano - Salvador)

\footnotetext{
${ }^{47}$ Carducho, Vicente, Diálogos del la pintura, su defensa, origen, esencia, definición, modos y diferencias. Madrid 1633 En casa de Francisco Martínez.
} 
- Alberto Durero de semetria de corpi humani y Reloges 48 (Cano - Salvador)

- Trato (sic) de la pintura de Joan Paulo Tomaso (en 4. $\left.{ }^{\circ}\right)^{49}$ (Cano - Salvador)

- Arte de pintura del Bruton (sic) (en $\left.4 .^{\circ}\right)^{50}$ (Cano - Salvador)

- Vite de pintori de Vasari (en $\left.4 .^{\circ}\right)^{51}$ dos tomos (Cano - Salvador)

- Joseph de Armeni de pintura en italiano (en $\left.4 .^{\circ}\right)^{52}$ (Cano - Salvador)

- Un libro con setenta estampas y dibujos (en $8 .^{\circ}$ ) (Cano - Salvador)

- Bolano de imaginibus ${ }^{53}$ (Cano - Salvador)

- Dos emblemas de Covarrubias con estampas (en 4. $\left.{ }^{\circ}\right)^{54}$ (Cano - Salvador)

- Los emblemas de Solorsano de D. Lorenzo Mateu en romano, dos tomos (en $\left.4 .^{\circ}\right)^{55}$ (Salvador)

- Imagenes de los dioses de los antiguos en italiano con estampas (en $\left.4 .^{\circ}\right)^{56}$ (Cano - Salvador)

- Examen de ingenios (en $\left.8 .^{\circ}\right)^{57}$ (Salvador)

- Discursos y epigramas del arte midoro (en $4 .^{\circ}$ ) (Cano - Salvador)

- Flors Sanctorum de Villegas (2. ${ }^{\circ}$ parte) ${ }^{58}$ (Cano - Salvador)

— " " de Ribadeneyra $\left(1 .^{\circ}, 2 .^{\circ}\right.$ y $3 .^{\circ}$ tomo) ${ }^{59}$ (Salvador)

- " " en italiano (en $4 .^{\circ}$ ) (Cano - Salvador)

- Flores historiales dos tomos (en $8^{\circ}$ ) (Cano - Salvador)

- Las empresas de Ruceli en estampas (Cano - Salvador) ${ }^{59}$ bis

- Triumphus Jesuchristi con estampas (en $\left.4 .^{\circ}\right)^{60}$ (Salvador)

- Dos libros de estampas de la Pasion ${ }^{61}$. (Cano - Salvador)

- Los discursos de los antiguos romanos con estampas (en 4..$^{\circ}$ ) (Cano - Salvador) ${ }^{61 \text { bis }}$

- Historias naturales de peces y animales de mar y tierra de Juan Justonio con estampas finas ${ }^{62}$. (Cano - Salvador)

- Metamorfosis de Ovidio con estampas.(en $\left.4 .^{\circ}\right)^{63}$ (Cano y Salvador)

${ }^{48}$ Durero, Alberto, Hierin sind begriffen vier Bücher von menschlicher Proportion. Nuremberg 1528. Traducción italiana, I quattro libri della proporzione umana, en italiano de Galucci, Venezia 1591 y 1594.

${ }^{49}$ Lomazzo, Gianpaolo, Trattato dell'Arte della Pittura, Milano, 1584.

${ }^{50}$ Butrón, Juan de, Discursos apologéticos en que se defiende la ingenuidad del arte de la pintura. Madrid 1626.

5 'Vasari, Giorgio, Le vite de' piu ecellenti pittori scultori e architettori scritte da..., Fiorenza 1568, Bologna 1647.

${ }_{52}$ Armenni, Giovanni Battista, De'veri precetti della pittura, Ravenna 1587.

${ }_{53}$ Bolando, Juan, Imago primi saeculi Societatis Jesu, Amberes 1640 . Escritor jesuita dedicado a redactar las vidas de los santos. Al grupo de escritores que se encargaron de este oficio se les denomina bolandistas.

${ }^{54}$ Covarruias y Orozco, Sebastián de, Emblemas Morales, Madrid 1610.

${ }^{55}$ Solorzano, Juan de, Emblemata regio-politica, Matriti 1652; Solorzano Pereira, Juan, Decadas.... de los emblemas de Don Juan de Solorzano Pereira, Valencia 1658.

${ }^{56}$ Cartari, Carlos, Le imagini degli Dei Antichi, nelli quali sono descritte le religioni degli antichi, riti e ceremonie loro, con l'agiunta di molte principali imagini e con l'esposizione in epilogo di ciascheduna e suo signficato, Venezia 1556. Poeta italiano del siglo xvı. De este libro se hicieron abundantes ediciones ilustradas con grabados sobre madera.

${ }^{57}$ Huarte de San Juan, Juan. Examen de ingenios para las sciencias, donde se demuestra la diferencia de habilidades que hay en los hombres y el género de letras que a cada uno le corresponde en particular. Es obra donde el que leyere con atención hallará la manera de su ingenio y sabrá escoger la ciencia en que más ha de aprovechar; y si por ventura la hubiese ya profesado, entenderá si atinó a la que pedia su habilidad natural. Baeza 1575, Valencia 1580, Madrid 1668, entre otras ediciones.

${ }_{58}^{58}$ Villegas, Alonso de, Flos Sanctorum, (2. ${ }^{\circ}$ parte), Zaragoza 1588, Toledo 1589.

${ }^{59}$ Rivadeneyra, Pedro de, Flos Sanctorum o libro de la vida de los santos, Barcelona, 1623, 1643, Madrid 1675.

59 bis Ruscelli, G., Le Impresse Illustri, Venecia, 1566.

61) Probablemente sea: Vives, Juan Luis, Triumphus Christi Jesu, Lovaina entre 1520-23; o Torrado de Guzmán, Pedro,

Triunfos de Jesús, en cantos de octava rima. Sevilla 1672.

${ }^{61}$ Puede ser que se trate de las «Pasiones» de Alberto Durero y Lucas de Leyden.

o1 bis Choul, Guillermo de, Discursos de la religión de los antiguos romanos y griegos, traducidos al castellano por Baltasar Pérez del Castillo, León de Francia, por Guillermo Rovillio, 1579 (con estampas).

${ }^{62}$ Desconocemos de que libro se trata.

${ }^{63}$ Ovidio Nasón, Publio, Las Metamorfosis, Burgos 1609 (con estampas) 
- Imagenes y edificios de la Tierra Santa (Cano - Salvador)

- Catalogo del purgatorio (Cano - Salvador)

- Biblia sacra de Lucduni ${ }^{64}$ (Cano - Salvador)

- Tratado de la Concepcion (en $\left.8 .^{\circ}\right)^{65}$ (Cano - Salvador)

- Retrato del pecador (en $8 .^{\circ}$ ) (Cano - Salvador)

- Arte de discreccion (en $8 .^{\circ}$ ) Fray Serafino de Fermo ${ }^{66}$. (Cano - Salvador)

- "de ingenios (en $\left.4 .^{\circ}\right)^{67}$ (Cano - Salvador)

- Prematica de los traxes (en $\left.8^{\circ}\right)^{68}$ (Cano - Salvador)

- Filiberti invencion del ben bastir ${ }^{69}$ (Cano - Salvador)

- Anatomia de Valiverde en castellano ${ }^{70}$ (Cano - Salvador)

- Plaza universal de todas las ciencias (en $\left.4 .^{\circ}\right)^{71}$ (Cano - Salvador)

- Teatro de figuras matemáticas con 60 estampas ${ }^{72}$ (Cano - Salvador)

- Teatro del mundo y del tiempo ${ }^{73}$ (Cano - Salvador)

- Imagen del mundo (en $\left.4 .^{\circ}\right)^{74}$ (Cano - Salvador)

- Gesolitica pieri en italiano ${ }^{75}$ (Cano - Salvador)

- Francisco Barosio Geometricum problemas (en $\left.4 .^{\circ}\right)^{76}$ (Cano)

- Geometria y pomo de oro (Cano - Salvador)

- Instrumentos de geometría (en $\left.8 .^{\circ}\right)^{77}$ (Cano - Salvador)

- Compendio geográfico de Sala (en $\left.4 .^{\circ}\right)^{78}$ (Salvador)

- Fabrica y uso de varios instrumentos (en $8^{\circ}$ ) (Salvador) ${ }^{78}$ bis

- Circulus matematicum de artes liberales ${ }^{79}$ (Cano - Salvador)

- Aritmetica de Bentallolo (en $\left.4 .^{\circ}\right)^{80}$ (Salvador)

\footnotetext{
${ }^{64}$ Biblia de Lyon.

${ }^{65}$ Justiniano Antist, Fray Vicente, Tratado de la Inmaculada Concepción de Nuestra Señora.., Valencia 1593, Sevilla 1615 .

${ }^{66}$ Fermo, fray Serafino de, Tratado provechoso de discreción. Burgos, 1553.

${ }^{67}$ Probablemente sea: Gracián y Morales, Baltasar, Arte de Ingenio, tratado de la agudeza, Madrid 1642.

${ }^{68}$ Debe estar en relación con las sucesivas pragmáticas sobre los modos del vestir. A este respecto se pueden citar: Declaración... Acerca de los trajes y vestidos....1537, Pragmática; Por un año más para que los hombres puedan gastar más los vestidos contra la Pragmática del once de Febrero de 1623, Prorrogación.

${ }^{69}$ Philibert de l'Orme, Nouvelles Inventions pour bien bastir, Paris, 1561.

${ }^{70}$ Valverde de Amusco, Juan de, Historia de la composición del cuerpo humano, Roma 1556.

${ }^{71}$ Suárez de Figueroa, Cristóbal, Plaza Universal de todas las ciencias y artes, Madrid 1615.

${ }^{72}$ Probablemente sea: Besson, Diego, Teatro de los instrumentos y figuras matemáticas, con las interpretaciones de cada figura hechas por Horacio Cardón., sin lugar de publicación en 1602.

${ }^{73}$ Probablemente sea: Ruiz de Corella, Jerónimo, Theatro, y descripción del mundo, y del tiempo. Amberes 1614.0 también puede ser: Galluci, G.P., Theatro del mundo y del tiempo, traducido del latín a la lengua castellana... Granada, 1606.

${ }^{74}$ Probablemente sea: Pérez de Oliva, Fernán, Imagen del Mundo. Palau afirma que esta obra está citada por el nieto de Pérez de Oliva, Ambrosio de Morales, que dice que «allí están graduados los más de los lugares municipales que agora están en España». Está obra no ha sido hallada. Palau y Dulcet, A., Manual del Librero Hispanoamericano, Barcelona 1961, tomo XIII, p. 99.

${ }^{75}$ Bolzán, Juan Pierino Valeriano, Hieroglyphica sine de sacri Egyptiorum......comentarii. Basilea, 1556, $1567,1575$.

${ }^{76}$ Barozzi, Francisco, Admirandum illud geometricum problema tredecim modis demonstratum. Venecia 1596.

${ }^{77}$ Probablemente sea: García de Céspedes, Andrés, Libro de instrumentos nuevo de geometría muy necesarios para medir distancias y alturas sin que intervengan números... demás desto, e ponen otro tratados, como es uno de conducir aguas y otro una questión de artillería en donde se ponen algunas demostraciones curiosas. Madrid 1606.

${ }^{78}$ Sala y Berart, Gaspar, Harmonía Geográfica de España, Barcelona, 1641. Agustino aragonés, profesor de teología en la universidad de Barcelona. Partidario de Luis XIII en la rebelión de Cataluña, éste le nombró su cronista.

78 bis Zaragoza y Vilanova, J., Fábrica y uso de varios instrumentos matemáticos, Madrid, 1675.

${ }^{79}$ Probablemente sea: Ciruelo, Pedro, Cursus quattuor mathematicarum artium liberalium, Alcalá 1516 . Uno de los primero libros de matemáticas y artes liberales impresos en España. Se ocupa extensamente de la música y otros temas como la aritmética, geometría y perspectiva.

${ }^{R 0}$ Ventallol, Ivan, La aritmética de Juan Ventallol traducida de lengua catalana, Tarragona 1619.
} 
- Noticia general de las artes liberales ${ }^{81}$ (Cano - Salvador)

- Aritmetica de Cortes ${ }^{82}$ (Salvador)

- Dos libros de Euclides (Cano - Salvador)

- Euclides posteriores ${ }^{83}$ (Cano - Salvador)

- Antonio machini matematicorum (en $\left.4 .^{\circ}\right)^{84}$ (Cano - Salvador)

- Tartaglia de numeri et misure ${ }^{85}$ (Cano - Salvador)

- Problemas de Varoquio (en $\left.4 .^{\circ}\right)^{86}$ (Salvador y Cano)

- Aritmetica de Saragosa (en 4. $\left.{ }^{\circ}\right)^{87}$ (Salvador)

- Esfera del padre Saragosa (en $\left.4 .^{\circ}\right)^{88}$ (Salvador)

- Esfera de Chaves en romano (en $\left.8 .^{\circ}\right)^{89}$ (Cano - Salvador)

- Esfera del sacro Bosco. (en 8..$^{\circ}{ }^{90}$ (Cano - Salvador)

- Sfera mundi comentum (en $4 .^{\circ}$ ) (Cano - Salvador) ${ }^{90}$ bis

- " " cum comentarais (Cano - Salvador)

- Beneyto tabula celestius ${ }^{91}$. (Cano - Salvador)

- Luminarium planetarium (Cano - Salvador)

- Campanela de Astrologia ${ }^{92}$ (Cano - Salvador)

- Problematum Astronomicum (Cano - Salvador)

- Astronomia del mundo de Ferrer (en $\left.4 .^{\circ}\right)^{93}$ (Salvador)

- Lunario de Cortes (en 8. ${ }^{\circ}{ }^{94}$ (Cano - Salvador)

- Pomponi de situ orbis (en $\left.8 .^{\circ}\right)^{95}$ (Salvador)

- Coronographia de Geronimo de Chabres (en $\left.4 .^{\circ}\right)^{96}$ (Cano - Salvador)

\footnotetext{
${ }^{81}$ Gutiérrez de los Ríos, Gaspar, Noticia general para la estimación de las artes y de la manera en que se conocen las liberales de las mecánicas y serviles, con una exhortación de la honra de la virtud y del trabajo contra los ociosos y otras particulares para personas de todos estados. Por el Licenciado Gaspar Gutiérrez de los Ríos, profesor de ambos derechos y letras humana, natural de la ciudad de Salamanca. Madrid 1600, por Pedro Madrigal.

${ }^{82}$ Cortés, Jerónimo, Aritmética práctica, Valencia 1659. Cortés era de origen valenciano.

${ }^{83}$ Euclides, Euclides posteriores, libri sex a X al XV, Roma 1574.

${ }^{84}$ Autor relacionado con la nota 266.

${ }^{85}$ Fontana, Nicolás, il Tartaglia, General trattato de' numeri e misure, Venezia 1556-60. Matemático de Brescia nacido en 1505 y desaparecido en 1557. De sobrenombre «tartaglia» por su tartamudez. Ocupó entre otras la cátedra de matemáticas en la universidad de Venecia.

${ }^{86}$ Barozzi, Francisco, Admirandum illud geometricum problema tredecim modis demonstratum. Venecia 1596.

${ }^{87}$ Zaragoza, José, Aritmética universal que comprehende el Arte Mayor y Menor, Algebra vulgar y espaciosa, Valencia 1669. Zaragoza era valenciano y jesuita.

${ }^{88}$ Zaragoza, José, Esfera en común celeste y terráquea, Madrid 1675.

${ }^{89}$ Chaves, Jerónimo, Tratado de la sphera que compuso el doctor Joannes de Sacrobusto con muchas aditiones. Agora nuevamente traducido del latin en lengua castallena por el bachiller Hyeronimo de Chaves; el qual añadió muchas figuras, tablas y claras demonstraciones junctamente con unos breves scholios, necesarios a mayor illustration, ornato y perfectio d'l dicho tractado. Sevilla 1545, en casa de Juan León.

${ }^{90}$ Sacro Bosco, Joannes, Spherae tractatus, in urbe Veneta 1531.

90 bis VV.AA., Sphera cum commentis in hoc volumine contentis, videlicet, Venecia, 1518.

${ }^{9 !}$ Desconocemos cuál es la tabla de Beneyto.

${ }^{92}$ Campanella, Tomás, Astrologicorum libi sex, 1620, desconocemos el lugar de edición. Famoso filósofo italiano 1568 1639, crítico implacable de la filosofía aristotélica, defensor de Telesio, perseguido y juzgado por el Santo Oficio, amigo de Galileo, huyó a Francia en donde fue reconocido, conoció a Descartes y murió. Sus conocimientos abarcaban las disciplinas más importantes de su época tales como, la teología, la filosofía, la medicina, la astrología, la adivinación, las matemáticas, la literatura. Su verdadero nombre fue Giovan Domenico y perteneció a la orden dominica.

${ }_{93}$ Ferrer, Leonardo, Astronomica curiosa y descripción del mundo superior y inferior, Valencia 1677.

${ }^{94}$ Cortés, Jerónimo, Lunario nuevo, perpetuo y general y pronóstico de los tiempos universalks. Madrid 1598. El non plus ultra del Lunario y pronóstico perpetuo general y particular de cada Reino y Provincia, Barcelona 1670.

${ }_{95}$ Pomponio, Mela, Desitu orbis, Valentia 1482.

${ }^{96}$ Chaves, Jerónimo, Chronographia o repertorio de los tiempos, 1561. Matemático, cosmógrafo y poeta sevillano. Ocupó la cátedra de Cosmografía de la Casa de Contratación. Tradujo versos de Marini, entre ellos la elegante décima, inserta en le libro 1, p. 68 del tratado de la pintura de Francisco Pacheco.
} 
- Dioscorides de Laguna ${ }^{97}$ (Cano - Salvador)

- Emblemas morales ${ }^{98}$ (Cano - Salvador)

- Prescripsionis de tropis (en $\left.8 .^{\circ}\right)$ (Cano - Salvador)

- Imago Militia de Espinosa ${ }^{99}$. (Cano - Salvador)

- Practica de la fortificacion de Roxas ${ }^{100}$ (Cano - Salvador)

- Discursí de las fortificationi de Carlo Feti ${ }^{101}$ (Cano - Salvador)

- Resolución de fortificación (en $8 .^{\circ}$ ) (Cano - Salvador) ${ }^{101}$ bis

- Practica y compendio de artillería (en $\left.4 .^{\circ}\right)^{102}$ (Cano - Salvador)

- Tratado de artillería (en 8..$^{\circ}$ ) Cristóbal Lechuga ${ }^{103}$ (Cano - Salvador)

- Compendio de la destresa de las armas de Naruais ${ }^{104}$ (Cano - Salvador)

- Regimiento nautico ${ }^{105}$ (Cano - Salvador)

- Cosme Bartuli del modo de mesurar de distancia (en 4..$^{106}$ (Cano - Salvador)

- Aristarqui de magnitudibus (en $\left.8 .^{\circ}\right)^{107}$ (Cano - Salvador)

- Navegación de Naxera (en $\left.4 .^{\circ}\right)^{108}$ (Cano - Salvador)

- Arte de navegar de Martin Cortes ${ }^{109}$ (Cano - Salvador)

- Regimiento de navegacion (en 8. ${ }^{\circ}{ }^{110}$ (Cano - Salvador)

- «de navegacion de Cespedes ${ }^{111}$ (Cano - Salvador)

- Tabula directionum (en $8 .^{\circ}$ ) (Cano - Salvador)

- Tabule primi mobilis maquini (Cano - Salvador)

- Belarmino Escala del cielo (en 8. $\left.{ }^{\circ}\right)^{112}$ (Cano y Salvador)

- Merlini Cocali (en 8. ${ }^{\circ}{ }^{113}$ (Cano - Salvador)

${ }^{97}$ Laguna, Andrés, Pedacio Dioscórides Anazarbeo, Lugduni 1554. Médico y humanista segoviano 1494-1560. Estudió en París, fue médico de Carlos V, viajó a Metz y Colonia en donde obtuvo gran reputación como médico y literato. Viajó a Roma fue doctor por la Universidad de Bolonia. En la Ciudad de los Papas fue médico de cámara del pontífice Julio III. Fue uno de los hombres más celebres de su tiempo. Publicó y tradujo abundantes obras de las cuales la más conocida, traducida a 10 lenguas, es el citado «Dioscórides».

${ }_{98}$ Alciato, Andrea, Emblemas Morales, Lyon, en casa de Matías Bonhome, 1554, Valencia 1654.

${ }^{99}$ Fernández de (E)Spinosa, Libro del arte militar, 1559. 1598.

${ }^{100}$ Rojas, Cristóbal, Teoría y práctica de la fortificación conforme a las medidas y defensas destos tiempos, Madrid,

${ }^{101}$ No hemos conseguido identificar los Discursos de Carlo Feti, quien por su nombre debió ser italiano.

101 bis Rojas, Cristóbal de, Compendio y breve resolución de fortificación, Madrid, 1613.

${ }^{102}$ Firrufino, Julio César, Práctica manual y breve compendio de artillería, Madrid 1626. Matemático madrileño nacido a finales del siglo $x \mathrm{v}$.

${ }^{103}$ Probablemente sea: Lechuga, Cristóbal, Discurso...en el que se trata de la artillería y de todo lo necesario a ella, con un tratado de fortificación, Milán 1611.

${ }^{104}$ Pacheco Narváez, Luis, Compendio de la filosofía y destreza de las armas de Jerónimo de Carranza, Madrid 1612. Maestro de esgrima y escritor de Baeza en la segunda mitad del siglo xvi. Fue profesor de matemáticas y maestro de esgrima personal de Felipe IV.

${ }^{105}$ Quizás sea: García de Palacio, Diego, Instrucción nautica para el buen uso y regimiento de las Naos, Méjico 1587.

106 Bartoli, Cosimo, Del modo de mesurare la distantie, superficie y corpi et tutte le cose terrene, Venetia, 1564.

${ }^{107}$ Samos, Aristarco de, Aritarchi di magnitudinibus et ditantics solis et lunce liber, Pisarri 1572.

${ }^{108}$ Nájera, Antonio de, Navegación especulativa...., Lisboa 1628, Madrid 1669.

${ }^{109}$ Cortés, Martin, Breve compendio de la sphera y de la arte de navegar con nuevos instrumentos y reglas, ejemplificado con muy sutiles demonstraciones, Sevilla 1551, en casa de Antón Alvaca.

${ }^{110}$ Medina, Pedro, Regimiento de Navegación, Sevilla 1563. Cosmógrafo Sevillano nacido hacia 1493. Su obra más importante es la citada.

${ }^{111}$ García de Céspedes, Andrés, Regimiento de navegación, Madrid 1606. Geógrafo español del siglo xvir. Fue junto a Antonio de Herrera cosmógrafo y cronista de Indias.

${ }^{112}$ Se refiere, probablemente a el venerable Roberto Francisco Rómulo Belarmino, cardenal, religioso jesuita y uno de los teólogos más conocido de su época (1542-1621). Escala espiritual para subir y ascender a conocer a Dios por los levantamientos y ascensiones del alma, por los pasos y escalones de las cosas criadas. Traducción de Fray Andrés Gil, en casa de Sebastián de Comellas, Madrid 1650.

${ }^{113}$ Seudónimo del poeta italiano, del siglo xv1, Teófilo Folengo. Poeta satírico, nacido en Mantua y que realizó sus estudios en Bolonia. Ingresó en la orden Benedictina de donde fue expulsado y, más tarde, readmitido. Entre sus obras jocosas; destacan imitaciones del Orlando el furioso de Ariosto, de la Eneida de Virgilio, y de la Divina Comedia de Dante. Su obra 
- Pietro Bembo (en 4. $\left.{ }^{\circ}\right)^{114}$ (Cano - Salvador)

- Tolomei Alexandrini ${ }^{115}$ (Cano - Salvador)

- Claudio Geomonises (Cano - Salvador) ${ }^{115 \text { bis }}$

- Belarminio (en 8. ${ }^{\circ}{ }^{116}$ (Cano y Salvador)

- Nicolai de Revolutionis ${ }^{117}$ (Salvador)

- Josepho de Beloindaico (en 8. ) $^{118}$ (Cano - Salvador)

- Litologia de Olmos (en 4. $\left.{ }^{\circ}\right)^{119}$ (Salvador)

- Vida de san Bruno (en 8. ${ }^{\circ}{ }^{120}$ (Cano - Salvador)

_ " de Quevedo (en 8..$^{121}$ (Salvador)

— " de Doña Maria de Servellon (en 4. ${ }^{\circ}$ ) ${ }^{122}$ (Salvador)

- Secretos de Don Alexos Piamonte (en $\left.8 .^{\circ}\right)^{123}$ (Cano - Salvador)

— " de la naturaleza (en $8 .^{\circ}$ ) ${ }^{124}$ (Cano - Salvador)

- Efemerides de Davit Origano (en $\left.4 .^{\circ}\right)^{125}$ (Cano - Salvador)

- Biblioteca de Pelliser (en 4. ${ }^{\circ}{ }^{126}$ (Salvador)

- Fenix de Pelliser (en $\left.8 .^{\circ}\right)^{127}$ (Cano - Salvador)

Zanitonella es una parodia de las Bucólicas de Virgilio y los sonetos amorosos de Petrarca. Además escribió el Orlandino, y la Moschoea, que entre tres libros narra las luchas entre moscas y hormigas. A su vez, tiene obras de carácter serio, tales como el poema latino Janus, la Palermitana, y la Hagiomachia.

${ }^{1 / 4}$ Cardenal y literato italiano (1470-1547). Protegido en Ferrara por Alfonso de Este y Lucrecia Borgia. Con Alđo Manucio emprendió la reforma de la ortografía italiana. Fue secretario particular del Papa León X, conoció a Rafael y fue gran coleccionista de antigüedades. Más tarde fue bibliotecario de san Marcos e historiógrafo de la República de Venecia. En 1539 es nombrado Cardenal y siendo obispo de Bérgamo participó en la composición de las obras del Concilio de Trento. Entusiasta de Petrarca y Cicerón, sus principales obras fueron: Rerum Veneticarum, libri XII, Gli Asolani (imitación de las Disputaciones Tusculanas de Cicerón y dedicada a Lucrecia Borgia), Le Prose, Le Rime, Carmina. Existe un retrato de Bembo en la Galería Barberini de Roma.

is Probablemente se refiera a Claudio Ptolomeo Alessandrino cuyo libro más famoso fue La Geografía di Claudio Ptolomeo Alessandrino, ridotta in volgare italiano da M Pietro Mathilo Senese, medio ecelentisimo, Venezia 1547. Salamanca 1547 por Juan Junta.

115 bis Clavius, Christoforus, Gnomonices, Roma, 1611. Tratado de relojes de sol.

${ }^{116}$ Se refiere, probablemente a el veneráble Roberto Francisco Rómulo Belarmino, cardenal, religioso jesuita y uno de los teólogos más conocido de su época (1542-1621). Su obra más significativa es De Controversis en la que defiende el poder indirecto del Papa sobre lo temporal. Sus obras completas se publicaron en Colonia en 1627.

117 Nicolai, Agustín, Historia dell'ultima revolucion della citta di Napoli, Amsterdam 1660.

118 Josefo, Flavio, De bello Judayco, Los siete libros que el historiador Flavio Josepho ecrivió de la guerra que tuvieron los judios con los romanos: y la destrucción de Jerusalem hecha por Vespasiano y Tito. Sevilla por Juan Croberger 1532. Madrid 1611.

${ }^{119}$ Olmo, José Vicente del, Lithología o explicación de las piedras y otras antigüedades halladas en las çanjas que se abrieron para los fundamentos de la capilla de $N .{ }^{a} S .{ }^{a}$ de los Desamparados de Valencia. En Valencia por Bernardo Nogués, junto al molino de la Rovella, 1653.

${ }^{120}$ Madariaga, Juan de, Vida del Serafico padre San Bruno, Patriarca de la Cartuja, con el origen, principio y costumbres desta Sagrada Religión. Valencia 1596. Cartujo y escritor valenciano, probablemente hijo del famoso calígrafo Pedro de Madariaga.

121 Tarsia, Pablo Antonio de, Vida de Don Francico de Quevedo y Villegas, Caballero de la Orden de Santiago, Secretario de Su Majestad y señor de la villa de la Torre de Iuan Abad. Madrid 1663.

122 Quizá: Corbera, Esteban, Vida y hechos maravillosos de Santa María de Cervellón, Barcelona 1639

${ }^{123}$ Ruscelli, Girolamo, Secretos del reverendo, D. Alejo Piamontes, Madrid 1624, Alcalá 1647.

${ }_{124}$ Probablemente sea: Navarro, Antón, Abecedario Virginal de Excelencias del Santísimo nombre de María, y propiedades naturales de piedras preciosas, aves, animales, fuentes, árboles y otros secretos de la Naturaleza, Madrid 1604.

${ }_{125}$ Origanus, David, Ephemerides novae annorum XXXVI nicipientes ab anno 1595 , Francoforti 1.599.

${ }^{126}$ Pellicer de Ossau Salas y Tovar, José, Biblioteca formada de los libros y obras públicas de D. José de Pellicer contiene'el' informe de su calidad i servicios, la cronologíate tedas sus oras mayores, y menores publicadas y ditiniguidas en el espacio dé 50 años continios i con observacióntes y escolios. El apendicé de iuchas que no estan impresas y el catalogo de los escritores que hablan de ellas o contra ellas dentro y fuera de España. Válencia 1674 . En casa de Jerónimo Vilagrasa, impresor de la ciudad y de la Santa: Inquisición, junto al molino de Rovella: Licenciado en filosofía cursó en Salamanca Cánones y Leyes. Muerto Lèónardo Argensola ocupó la vacante de Cronista del Reino de Castilla y más tarde de Aragón.

* 127 Pellicer de Ossau Salas y Tovar, José, El Fénix y su historia natural ecrita en 22 eercitaciones, diatribas, o' capitulos al Sr. D. Luis Méndez de Haro,. Gentil H. de la Cámara de S. M. por José Pellicer..... cronista de los Reynos de Castilla.. Madrid imprenta del Reino 1630 a costa de Pedro Coello, mercader de libros. $\ldots$. 
- Perdida de España (en 8. $)^{128}$ (Cano - Salvador)

- Destruccion de las Indias (en 8..$^{\circ}{ }^{129}$ (Cano y Salvador)

- Discursos políticos de Navarrete ${ }^{130}$ (Cano - Salvador)

- Empresas de Fabricio con estampas (en $4 .^{\circ}$ ) (Cano - Salvador) ${ }^{130}$ bis

- "políticas de Saavedra con estampas finas (en $\left.4 .^{\circ}\right)^{131}$ (Salvador)

— " de Capasio (en 4..$^{\circ}$ (Cano - Salvador) ${ }^{131 \text { bis }}$

- Honras de Felipe IV en Madrit con estampas ${ }^{132}$ (Salvador)

- Tortosa fidelisima (en $\left.4 .^{\circ}\right)^{133}$ (Cano - Salvador)

- Montessa ilustrada de Samper ${ }^{134}$ (Salvador)

- Antiguedades de Segorbe (en $\left.4 .^{\circ}\right)^{135}$ (Salvador)

- Anales de Aragon de Zurita, seis tomos ${ }^{136}$ (Salvador)

- Suma de varones ilustres ${ }^{137}$ (Cano - Salvador)

— " de Vega dos tomos ${ }^{138}$ (Cano - Salvador)

- Cronica del Cid (Cano - Salvador)

- Corte del Rey Momo (en 8. ${ }^{\circ}$ ) (Cano - Salvador)

- Los Reyes nuevos de Toledo (en $\left.4 .^{\circ}\right)^{139}$ (Salvador)

- Los Cesares de Permegia ${ }^{140}$ (Cano - Salvador)

- Memorial de Valencia de Servellon (Salvador) ${ }^{140 \text { bis }}$

- Solo Madrit es corte (en 4. ${ }^{\circ}{ }^{141}$ (Salvador)

${ }^{128}$ Luna, Miguel, La verdadera historia del Rey don Rodrigo, en la cual e trata la causa principal de la pérdida de España y la conquista que hizo de ella Miramamolin Almançor. Compuesta por el sabio alcayde Abulacacim Tarif Abentarique, de nación árabe. Nuevamente traducida de la lengua arábiga por Miguel de Luna. Granada 1592. Miguel de Luna fingió encontrar el manuscrito en la biblioteca de el Escorial y se inventó la obra. Hubo durante mucho tiempo una mistificación literaria de eta obra. Luna, morisco, fue interprete oficial de árabe en Granada.

${ }^{129}$ Las Casas, Fray Bartolomé de las, Brevísima relación de la destrucción de las Indias, Sevilla 1552 . En casa de Sebatián Trujillo.

${ }^{130}$ Probablemente sea: Navarrete, Antonio de, Política de la verdad, alivio de este reino útil para el Príncipe que la gobernare. Nápoles 1620 .

130 bis Fabrizio, Gilio da, Imagines Illustrium ex Fulvii Ursini Biblioteca, Auterpiae a Teodoro Gallaleo, empresas comentarius, 1606.

${ }^{131}$ Saavedra Fajardo, Diego, Empresas politica e idea de un príncipe político cristiano representada en cien empresas por Don.... Valencia 1658, 1664, 1665.

131 bis Capaccio, G.C., Delle Impresse, Nápoles, 1592.

${ }_{132}$ Rodríguez de Monforte, D, Pedro, Honras fúnebres del Rey Felipe IV, Madrid 1666.

${ }^{1.33}$ Miravall y Forcadell, Vicente de, Tortosa, ciudad fidelisima y ejemplar, Madrid 1641.

${ }^{134}$ Samper, Hipólito, Montesa Ilustrada, Valencia 1668. Grabador Pedro de Villafranca.

${ }^{135}$ Probablemente sea: Villagrasa, Francisco de, Antigüedad de la Iglesia Catedral de Segorbe y catálogo de sus obis pos, Valencia 1664.

${ }^{136}$ Zurita y Castro, Jerónimo, Anales de la Corona de Aragón, Zaragoza 1621-23. VVEE.

${ }^{137}$ Sedeño, J. Summa de varones ilustres en la cual se contienen muchos dichos, sentencias y grandes hazaña y cosas memorables. De doscientos veinte y cuatro famosos. Tanto emperadores como reyes, capitanes que ha havido de todas las naciones, desde principios del Mundo hasta quasi nuestros tiempos por la orden ABC. Median del Campo 1551 . Dirigida a Felipe II.

${ }^{138}$ Quizá: Vega, Andrés, De justificatione, gratia fide, operibus et meritis quindecim (Venecia 1546)y Tridentini decreti de justificatione expositio et defensio libris XV distincta (Venecia 1548). Ambos vueltos a publicar por el Jesuita san Pedro Canisio en Colonia en 1572. Carlos V le envió a Trento debido a su amplio saber teológico.

${ }^{139}$ Lozano, Cristóbal, Los Reyes Nuevos de Toledo, descríbense las cosas más augustas y notables de esta ciudad imperial quienes fueron los Reyes Nuevos, sus virtudes, sus hechos, sus proezas, sus hazañas, y la Real Capilla, que fundaron en la Santa Iglesia, mausoleo sumptuoso donde descansan sus cuerpos. Madrid 1667.

${ }^{140}$ Mejía, Pedro, Historia imperial y cesárea, en la cual se contienen las vidas y hechos de todos los Césares desde Julio Cesar hasta el emperador Maximiliano. Sevilla 1545. Colección de biografías de emperadores que alcanzó gran fama. Mejía fue historiador, poeta y didáctico español. Estudió leyes en Salamanca y fue diestro en el manejo de las armas. Llegó a ser caballero veinticuatro de la ciudad de Sevilla. Fue amigo de Hernando Colón y mantuvo correspondencia en latín con Luis Vives. Fue cronista de Carlos V y murió en Sevilla en 1552, escribiendo su epitafio Benito Arias Montano.

140 bi Cervellón, Gerardo de, Defensa de la ciudad de Valencia sobre la possesion de los castillos, villas y baronías de Paterna, Benaguacil y La Puebla contra la Casa de los Duques de Segorbe, Valencia, 1660.

${ }^{141}$ Núñez de Castro, Alonso, Solo Madrid es corte, Madrid 1658. 
- Itinerario historico de Andrade dos tomos (en $\left.4 .^{\circ}\right)^{142}$ (Salvador)

- Historia de las Indias de Bartolome de las Casas ${ }^{143}$ (Salvador)

— " de Madrit de Quintana ${ }^{144}$ (Cano - Salvador)

- " oriental de Fernan Mendes ${ }^{145}$ (Cano - Salvador)

_ " de Valencia de Escolano, segunda parte ${ }^{146}$ (Salvador)

— " de España de Beuter ${ }^{147}$ (Salvador)

- " de las Indias de Bartolome de las Casas (Cano y Salvador)

— " de las islas de Gina (santo Domingo) (Cano - Salvador) ${ }^{147 \text { bis a }}$

_ " de Gile (Cano - Salvador) ${ }^{147}$ bis b

- " de las Filipinas (en $4 .^{\circ}$ ) (Cano - Salvador)

— " varia de Italia (en $8 .^{\circ}$ ) (Cano - Salvador) ${ }^{147 \text { bis c }}$

- " de Tartalia (en $\left.80^{\circ}\right)^{148}$ (Cano - Salvador)

- " general de aves y animales (en $\left.4 .^{\circ}\right)^{149}$ (Salvador)

- " del Rey Don Rodrigo (en 4..$^{\circ}$ ) (Cano - Salvador)

- " pontifical cinco tomos ${ }^{150}$ (Cano - Salvador)

— " de la virgen del Puig (en 8. $\left.{ }^{\circ}\right)^{151}$ (Salvador)

- Origen de los turcos (en $\left.8 .^{\circ}\right)^{152}$ (Salvador)

— " de las Indias (en $8 .^{\circ}$ ) (Cano - Salvador)

- Guerras de Francia de Gaterino ${ }^{153}$ (Salvador)

_ " de Flandes de Bentigollo ${ }^{154}$ (Cano - Salvador)

— " de Granada (en $\left.8 .^{\circ}\right)^{155}$ (Cano - Salvador)

${ }^{142}$ Andrade, Alonso de, Itinerario historial que debe guardar el hombre para caminar al cielo, Madrid $1648,1657$.

${ }^{143}$ Las Casas, Fray Bartolomé, Historia de las Indias ahora por primera ves dada a luz por el Marqués de Fuensanta del Valle, Madrid 1675. Esta historia fue empezada en 1552 y acabada en 1559. Había de constar 6 tomos o partes pero sólo tiene tres, puesto que Casas murió en 1566. Véase al respecto Palau y Duçet, Manual del Bibliófilo.... Tomo III, p. 247.

${ }^{144}$ Quintana, Jerónimo, Historia de la antigüedad, nobleza y grandeza de la coronada villa de Madrid, Madrid 1629. Agulló y Cobo, M, «EL licenciado J.Q. cronista de Madrid». 1975, ciclo de conferencias sobre madrileño ilustres, Volumen 5 .

${ }^{145}$ Méndez Pinto, Fernán, Historia oriental de las peregrinaciones de Fernán Mendes Pinto Portugués, a donde se escriven muchas y muy extrañas cosas que vió, y oyó en los Reinos de la China, Tartaria, Sorano, que vulgarmente se llama Siam Calamiñám Pegun, Martanan, y otros muchos de aquellas partes orientales, de que en estas nuestras de Occidente ay muy poca o ninguna noticia... Traducida al castellano por el licenciado Francis de Herrera Maldonado, canónigo de la santa Iglesia Real de Arbas...En Madrid 1620. Dedicada a Felipe III.

${ }^{146}$ Escolano, Gaspar, Decada primera de la historia de la insigne y coronada ciudad y reino de Valencia, Valencia 1610 11,2 vol.

${ }^{147}$ Beuter, Pedro Antonio, Crónica General de España, Valencia 1550, 1604

147 bis a Juan González de Mendoza, Historia de las cosas más notables, ritos... de la China, Roma, 1585.

147 bis b Leonardo Argensola, B. y Molina, J.A., Compendio de Historia y Geografia natural y nivil del Reino de Chile.

147 bis c Guicciardini, F., La historia d'Italia, riscontrata con tutti gli altri historici et auttori per Thomaso Porcacchio, Trevisi, 1604.

${ }^{148}$ Puede referirse: Centeno, Amaro, Historia de las cosas de oriente. Primera y segunda parte. Contiene una descripción general de los reinos de Asia... La historia de los tártaros... Las cosas de Egipto... La historia de Hierusalem... Córdoba 1595.

${ }^{149}$ Aristóteles, Historia general de Aves y animales traducida del latin en romance y añadida de otros autores griegos y latinos por Diego de Funes y Mendoza. Valencia, por Pedro de Patricio Mey, junto a San Martín, 1621. Funes escribió Las gradas del amor de Dios en teoría y práctica. Huesca 1635.

${ }^{150}$ Probablemente se trate de la obra de Fray Gonzalo de Illecas, Historia pontifical católica, Burgos 1564, Barcelona 1606.

151 Boil, Fray Francisco, Nuestra Señora del Puig, Valencia 1631

${ }^{152}$ Roca, Vicente, Historia en la cual se trata de la origen y guerras que han tenido los turcos, desde su comienzo hasta nuestros días: con muy notables sucesos que en diversas gentes y naciones les han acontecido. Valencia 1556 . V. Roca fue un noble valenciano.

${ }_{153}$ Caterino Dávila, Enrico, Historia de las guerras civiles de Francia. Traducido por Basilio Varen Soto. Madrid 1651.

${ }^{154}$ Bentivoglio, Guido, Histoire des guerres civiles de Flandres, Paris 1620, Colonia 1634, 39.

${ }^{155}$ Hurtado de Mendoza, Diego, Guerra de Granada. Hecha por el Rey de España don Felipe II nuestro Señor contra los moriscos de aquel reino, sus rebeldes. Lisboa 1627. 
- Los Anales de Cornelio Tasito en romance ${ }^{156}$ (Cano - Salvador)

- Corona gótica castellana (en 4. ${ }^{\circ}$ ) (Salvador) ${ }^{156}$ bis

- Grandezas de Constantinopla ${ }^{157}$ (Cano - Salvador)

- Fiestas de San Juan de Malta (en $4 .^{\circ}$ ) (Cano - Salvador)

- Fiestas de la Concepcion y Virgen Desamparados (en $4 .^{\circ}$ ) (Salvador)

- " de santo Tomas de Villanueva (en $4 .^{\circ}$ ) (Salvador)

- Origine de Vinesia (en $4 .{ }^{\circ}$ ) (Cano - Salvador)

- Descripcion de las Indias (Cano - Salvador)

- " de mapa (en 4. ${ }^{\circ}$ ) (Cano - Salvador)

- Conquista de Peru (Cano - Salvador)

- " de las islas Malucas (Cano - Salvador)

— " de Rodas (en 8. $\left.{ }^{\circ}\right)^{158}$ (Cano - Salvador)

- Cargos militares (en $\left.4 .^{\circ}\right)^{159}$ (Cano - Salvador)

- Escuela de la sabiduría (en $\left.4 .^{\circ}\right)^{160}$ (Cano - Salvador)

- Morales de San Gregorio ${ }^{161}$ (Cano - Salvador)

- Silva de varia eleccion ${ }^{162}$ (Cano - Salvador)

- El Hijo de Davit $1^{\circ}, 2 .^{\circ}$ y $3 .^{\circ}$ tomo (en $\left.4 .^{\circ}\right)^{163}$ (Salvador)

- Monte Calvario dos tomos (en $\left.8 .^{\circ}\right)^{164}$ (Cano-Salvador)

- Filosofia de Moya (en 4. $\left.{ }^{\circ}\right)^{165}$ (Cano - Salvador)

- Razon de estado de Botero (en 8. ${ }^{\circ}{ }^{166}$ (Cano - Salvador)

- Sueño politico (en $\left.4 .^{\circ}\right)^{167}$ (Salvador)

- Consejos políticos (en $\left.4 .^{\circ}\right)^{168}$ (Cano-Salvador)

- Lagrimas de los justos (en $4 .^{\circ}$ ) (Cano - Salvador)

- Medula de Busenbau en romance (en $\left.4 .^{\circ}\right)^{169}$ (Salvador)

- Consolacion de Boecio (en 8. ${ }^{\circ}{ }^{170}$ (Cano - Salvador)

156 Tácito, Cayo Cornelio, Los Anales, Madrid 1614. Abundantes y diversas ediciones.

156 bis Saavedra Fajardo, D., Corona Gothica Castellana y Austríaca políticamente ilustrada, Münster, 1664.

${ }^{157}$ Almosnino, Rabi Moysen, Extremos y Grandezas de Constantinopla. Madrid 1638.

${ }^{158}$ Fontano, Jacome, La muy lamentable conquista y cruenta batalla de Rodas. Sevilla 1526 . Traducida del latín por Cristóbal de Arcos.

${ }^{159}$ Brancachio, Fray Lelio, Cargos y preceptos militares para salir valiente soldado, así en la infantería, caballería como artilleria. Barcelona 1639. Traducido del italiano por Idelfonso Escavino.

${ }^{160}$ Zaragoza de Heredia, Miguel, Escuela de la perfecta y verdadera sabiduría, donde se muestra la obligación que todos tenemos de servir perfectamente a Dios, y de to que cada uno tiene en su estado. Madrid 1612.

${ }^{161}$ Gregorio I, el Magno, Expositio in librum Job sive Moralium libri XXXV. Lugduni, 1522.

${ }^{162}$ Mexía, Pedro, Silva de varia lección. Sevilla 1540. Dirigido al emperador Carlos V... compuesto por... A la manera de Silvas sin guardar orden en los propositos, se tratan los capitulos muchas y diversas materias, historias, exemplos y questiones de varia lección y erudición.

${ }^{16.3}$ Podría referirse a: Lorea, Antonio de, El grande hijo de David, Cristo N. ${ }^{\circ}$ S. ${ }^{\circ}$. Historia evangélica, moral, política y predicable. Madrid 1673. O también Lozano, C., El gran hijo de David más perseguido (tres partes 1663-1665-1673).

${ }_{164}$ Probablemente sea el libro de Antonio de Guevara, Monte Calvario compuesto por.... Trata el autor en este libro todos los misterios del monte Calvario: desde que Christo fue a muerte condenado por Pilato hasta que por Joseph y Nichodemus fue en el sepulcro metido.. Valladolid 1545. Hoy en día, no se conocen ejemplares de esta obra.

${ }^{165}$ Moya Pérez, Juan, Philosophia secreta. Donde debaxo de historias fabulosas se contiene mucha doctrina provechosa a todos los estudios. Con el origen de los idolos o dioses de la gentilidad. Es materia muy necesaria para entender Poetas y Historiadores. Ordenado por el Bachiller Juan Péres de Moya. Madrid 1584.

${ }^{166}$ Botero, Juan, Razón de estado con tres libros de la grandeza de las ciudades, Burgos 1603. Dikersas ediciones en italiano y castellano. Libro contestatario de el Príncipe de Maquiavelo.

${ }^{167}$ Fonseca Almeyda, Melchor de, Sueño político. Madrid ca. 1650. Es una sátira política contra Felipe IV y el Conde Duque.

${ }^{168}$ Enríquez y Zúñiga, Juan, Consejos políticos y morales. Cuenca 1634.

${ }^{169}$ Busembaum, Hermann, Medulla theologiae moralis, Munster 1645, Madrid 1664 en castellano

${ }^{170}$ Boecio, Anicio Manlio Torcuato Severino, De consolatione philosophiae, Sevilla 1521 . Abundante ediciones, Madrid, Valladolid. 
- Fray Pablo de Santa Maria (en 8. ${ }^{\circ}{ }^{171}$ (Cano - Salvador)

- Exercicios del padre San Ignacio (en $\left.8 .^{\circ}\right)^{172}$ (Cano - Salvador)

- Obras de Juan Perez de Moya cuatro tomos ${ }^{173}$ (Salvador)

- Vergel de la Divina escritura de Nuñes de Andrade ${ }^{174}$ (Cano - Salvador)

- Lagrimas panegiricas de Montalban (en $\left.4 .^{\circ}\right)^{175}$ (Cano - Salvador)

- Rimas de D. Gabriel Bocangel (en $8^{\circ}{ }^{\circ}{ }^{176}$ (Cano - Salvador)

- Epitetos de Cabedo (en $\left.8 .^{\circ}\right)^{177}$ (Cano - Salvador)

- Republica literaria (en $\left.8 .^{\circ}\right){ }^{178}$ (Salvador)

- Tesoro de la memoria (en $\left.8^{\circ}\right)^{179}$ (Salvador)

- Sentencias de Guzman ${ }^{180}$ (Cano - Salvador)

- Arte poetica español (en $\left.4 .^{\circ}\right)^{181}$ (Cano - Salvador)

- Maravillas de la Gracia dos tomos (en 4..$^{\circ}{ }^{182}$ (Cano - Salvador)

- Avisos de Santa Theresa dos tomos ${ }^{183}$ (Cano - Salvador)

- Reyno de Dios de Sanchis ${ }^{184}$ (Salvador)

- Eustorgio y Clarirene (en4. $\left.{ }^{\circ}\right)^{185}$ (Cano - Salvador)

- Gustavo Adolfo (en 4..$^{\circ}$ ) (Cano - Salvador)

- Vida del Señor Patriarca (en $\left.4 .^{\circ}\right)^{186}$ (Salvador)

- Relasiones del cardenal Bentibollo ${ }^{187}$ (Cano - Salvador)

- Espejo de príncipes (en $\left.4 .^{\circ}\right)^{188}$ (Cano - Salvador)

- Lagrimas de la noblesa (en $\left.4 .^{\circ}\right)^{189}$ (Salvador)

- Historia de los corporales (en $80^{\circ}$ ) (Cano - Salvador)

- Los titols de Cataluña Rosello y Serdaña (Salvador)

- Palafoix Historia real Sagrada ${ }^{190}$ (Salvador)

\footnotetext{
W71 Probablemente alguna de sus obras; Suma de corónicas de España, Edades trovadas.... Judío burgalés de notable influencia en su época (1350-1435), se convirtió al cristianismo después de haber oído la predicación de San Vicente Ferrer. Llegó a ser obispo de Burgos.

${ }^{172}$ Loyola, San Ignacio, Exercicios espirituales del B.P. Ignacio de Loyola. Roma 1615, en el colegio roano de la Compañía.

173 Pérez de Moya, Juan, Comparaciones o similes para vicios y virtudes, Valencia 1599.

${ }^{174}$ Núñez de Andarde, Andrés, Vergel de la escritura divina, Córdoba 1600.

${ }^{175}$ Grande de Tena, P., Lágrimas panegíricas a la temprana muerte del gran poeta... Doctor Juan Pére: de Montalbán. Madrid, 1639.

176 Bocángel y Unzueta, Gabriel, Rimas y prosas, Madrid 1627. También La lira de las musas de humanas y sagradas.

${ }^{177}$ Quevedo y Villegas, Francisco de, Epiteto y Phocilides en español con consonantes, Madrid 1635.

${ }^{178}$ Saavedra Fajardo, Diego, República literaria, juicio de arte y ciencias. Madrid 1655. Pseudónimo de D. Claudio Antonio de Cabrera.

${ }^{179}$ Vargas, Miguel de, Tesoro de la memoria y del entendimiento y arte fácil para toda sabiduría. Madrid‘1658.

${ }^{180}$ Guzmán, Francisco de, Sentencias Generales Francisco de Guzmán, Lérida 1576, Lisboa 1598.

${ }^{181}$ Díaz Rengifo, Juan, Arte poética española, con una fidelíssima sylva de consonantes comunes propios, esdrúxulos y reflexos y un divino estímulo del Amor de Dios, por Juan Diez Rengifo, Salamanca 1592; Madrid 1606-1644.

${ }^{182}$ Tal vez se trata de una obra de San Juan de la Cruz.

183 Cepeda y Ahumada, Santa Teresa, Avisos espirituales de la madre Teresa de Jesús fundadora de los monasterios de monjas carmelitas descalzas, dados a todas las religiosas y sus hijas. Barcelona, Lorenzo Den, 1641, Madrid 1647.

${ }^{184}$ Sánchez, Pedro, Libro del reyno de Dios y del camino..., Barcelona 1605, Valencia 1611.

${ }^{185}$ Suárez Mendoza y Figueroa, Enrique, Eustorgio y Clorilene, historia moscovica, Madrid 1629. Obra inspirada en el Persiles y Segimunda de Cervantes.

186 Escrivá, Vida del Beato don Juan de Ribera, Valencia 1640.

${ }^{187}$ Bentivoglio, Guido, Relationi fatte in tempo delle mie nuntiature di Fiandre e di Francia, Colonia 1629.

${ }^{188}$ Aunque existen varias obras con títulos parecidos como por ejemplo la de D. Baltasar de Zúñiga, Espejo de príncipes, Méjico; la de Martín de Carvalho Villaboas, Espejo de príncipes y ministros, Milán 1598 o la de Diego Ortúñez de Calahorra, Espejo de príncipes y caballeros, creemos que en nuestro caso se trata de la obra de Francisco Monzón, Espejo del príncipe Cristiano; que trata de cómo criar un príncipe, Lisboa 1544, 1571.

${ }^{189}$ Probablemente sea: Padilla, María Luisa, Condesa de Aranda, Lágrimas de la nobleça... al Excmo Sr. D. Antonio Ximénez de Urrea, Conde de Aranda, Zaragoza 1639.

${ }^{190}$ Palafox y Mendoza, Juan de, Historia Real Sagrada, luz de príncipes, Valencia 1660. VVEE.
} 
- Examen de revelaciones (en $\left.4 .^{\circ}\right)^{191}$ (Salvador)

- Don Quixote $1 .^{\circ}$ y $2 .^{\circ}$ parte de impresion de Bruxelas ${ }^{192}$ (Cano - Salvador)

- Obras del padre Falconi (en $\left.4 .^{\circ}\right)^{193}$ (Salvador)

- Libro de la Minerva (en 4 ) (Cano - Salvador)

- Don Jose de Valdivieso (en $\left.4 .^{\circ}\right)^{194}$ (Cano - Salvador)

- Cronicon de D. Juan Tavera (en $4 .^{\circ}$ ) (Cano - Salvador)

- Seneca impugnado (en $\left.4 .^{\circ}\right)^{195}$ (Salvador)

- Orlando el furioso (en $\left.4 .^{\circ}\right)^{196}$ (Cano - Salvador)

- Suma Pompilio (en 4..$^{197}$ (Cano - Salvador)

- Proverbios de Seneca (en 8. ${ }^{\circ}{ }^{198}$ (Cano - Salvador)

- Caton (en 8. $\left.{ }^{\circ}\right)^{199}$ (Cano - Salvador)

- Ciceron de oficios (en $\left.8 .^{\circ}\right)^{200}$ (Cano - Salvador)

- Sol de academias (en $\left.8 .^{\circ}\right)^{201}$ (Salvador)

- Romancero espiritual (en8. $\left.{ }^{\circ}\right)^{202}$ (Cano - Salvador)

- El Cortesano por Boscan (en 8. ${ }^{\circ}{ }^{203}$ (Cano - Salvador)

- El Dante con comento en italiano ${ }^{204}$ (Cano - Salvador)

- Las Lusiadas de Camoens ${ }^{205}$ (Cano - Salvador)

- Tabula Alfonsina (en 4. $\left.{ }^{\circ}\right)^{206}$ (Cano - Salvador)

- Tesoro de poesías varias (en $\left.4 .^{\circ}\right)^{207}$ (Cano - Salvador)

— " de la memoria (en 8..$^{\circ}{ }^{208}$ (Salvador)

- Suma de Villalobos, dos tomos ${ }^{209}$ (Salvador)

- Valerii Martini De propietatibus (Cano - Salvador)

${ }^{191}$ Planes, Jerónimo, Tratado del examen de las revelaciones verdaderas y falsas, y de los raptos. Valencia 1634.

${ }^{192}$ Cervantes Saavedra, D. Miguel de, El ingenioso hidalgo D. Quijote de la Mancha. Bruselas, por Roger Velpius y Humberto Antonio, impresores de sus altezas, en l'Aguila de Oro, cerca de Palacio, 1611. Segunda parte del ingenioso hidalgo..., Bruselas 1616 .

${ }^{193}$ Falconi, Juan, Obras espirituales del venerable Padre Falconi, del Orden Calçado de $N .{ }^{a} S{ }^{a}$ de la Merced, $1 .^{a}$ Cartilla. Zaragoza 1631.

${ }^{194}$ Probablemente alguna obra del poeta español José de Valdivieso (1560-16389, amigo de Cervantes y otros importantes escritores de su tiempo. Entre sus obras destacan, el Romancero espiritual del Santísimo Sacramento o sus Autos Sacramentales (El villano en su rincón, el hospital de los locos etc.).

${ }^{195}$ Núñez de Castro, Alfonso, Séneca impugnado de Séneca. Madrid 1650-1.

${ }^{196}$ Ariosto, Ludovico, Orlando el Furioso, primera edición completa y en la cual se incluía un retrato de Tiziano fue la de Ferrara de 1534. Venecia, 1554.

${ }^{197}$ Quizá: Pompilio, Marco Andrónico, escritor romano del siglo I a. J.C. Profesor de retórica en Roma y dejó una obra titulada Annalium Ennii Elenchi.

${ }^{198}$ Séneca, Lucio Anneo, Proverbios. Diversas ediciones en castellano, (1482, 1500, 1510, 1512, 1552); Proverbios, por J.M.C. Valenciano, Amberes 1555.

${ }^{199}$ Catón, Dionisio, Liber Catonis philosophiae = Disticha moralia, nomine Catonis inscripta, Antverpie 1563, VVEE. Libro utilizado en la Edad Media como manual de educación.

${ }^{200}$ Cicerón, Marco Tulio, De Oficiis. Salamantinae, 1567.

${ }^{201}$ Sol de Academias o Academia de Soles. En los variados ingenios de Valencia que le celebraron y en la hermosura y nobleza que la asistieron su Mecenas, el ilustrísimo señor D. Basilio de Castelvi y Ponce. Valencia, Juan Lorenzo Cabrera, delante de la Diputación, 1658.

202 Valdivieso, José, Romancero espiritual del Santísimo Sacramento, Toledo 1612.

${ }^{203}$ Castiglione, B. Los cuatro libros del cortesano, gora nuevanente traducidos en lengua castellana por Boscán (Almogaver, Juan) Barcelona 1534. La traducción se hizo gracias a la insistencia de su gran amigo Garcilaso de la Vega.

${ }^{204}$ Alighieri, Dante, La Divina Comedia. Existen abundantes ediciones con comentario en italiano. En el siglo xvi son famosas las comentadas por Vellutello (Venecia 1544) y Bernardo Dani da Luca (Venecia 1568).

${ }^{205}$ Camoens Vaz de, Luis, Lusiadas de Luis Camoens, Madrid 1639.

${ }^{206}$ Tablas Alfonsinas, Toledo 1252. Trabajan en éstas, Jehudah-bar-Mosch-ben-Mosca y Rabi Zag-ben-Zagut-Melitolah.

${ }^{207}$ Padilla, Pedro de, Tesono de varias poesías. Madrid 1580. Dirigido al Almirante de Castilla, D. Luis Enríquez de Cabrera.

${ }^{208}$ Véase nota ${ }^{\circ}{ }^{1} 180$

${ }^{209}$ Villalobos, Enrique de, Suma de a Teología monal y canónica, Madrid 1658. VVEE. 
- Cronica del rey D. Juan (dos tomos) ${ }^{210}$ (Salvador)

- Discursos del Dr. Melchor Fuster (en $\left.4 .^{\circ}\right)^{211}$ (Salvador)

- El Sabio maximas del padre Grau (en $\left.4 .^{\circ}\right)^{212}$ (Salvador)

- Aviso del Parnaso (en $\left.4 .^{\circ}\right)^{213}$ (Cano - Salvador)

- Obras de fr. Luis de Granada ${ }^{214}$ (Cano - Salvador)

- Simbolo de la fe del mismo ${ }^{215}$ (Cano - Salvador)

- Confesiones de San Agustin (en 4. $\left.{ }^{\circ}\right)^{216}$ (Cano - Salvador)

- Las Trescientas de Juan de Mena (en 4. $\left.{ }^{\circ}\right)^{217}$ (Cano - Salvador)

- Jerusalem conquistada (en $\left.4^{\circ}\right)^{218}$ (Cano - Salvador)

- " libertada (en $\left.4 .^{\circ}\right)^{219}$ (Cano - Salvador)

- Menosprecio de la Corte (en $\left.4 .^{\circ}\right)^{220}$ (Cano - Salvador)

- Coplas de D. Jorge (en $\left.4 .^{\circ}\right)^{221}$ (Cano - Salvador)

- Ovidio Metamorfosis (en $\left.4 .^{\circ}\right)^{222}$ (Cano y Salvador)

- Morales de Plutarco antiguo ${ }^{223}$ (Cano - Salvador)

- Advertencias de Reyes a Principes (en 4. $\left.{ }^{\circ}\right)^{224}$ (Cano - Salvador)

- Don Felipe el prudente (en $\left.4 .^{\circ}\right)^{225}$ (Cano - Salvador)

- Dichos y hechos de Felipe segundo (en 8. ${ }^{\circ}{ }^{226}$ (Cano - Salvador)

- Devocion a Maria (en $\left.4 .^{\circ}\right)^{227}$ (Salvador)

- Primera parte del arte de escribir de Casanova ${ }^{228}$ (Salvador)

- Refranes castellanos (en $\left.4 .^{\circ}\right)^{229}$ (Cano - Salvador)

- Vocabulario de Antonio antiguo ${ }^{230}$ (Cano - Salvador)

- Arte de gramatica francesa y española (en $4 .^{\circ}$ ) (Cano - Salvador)

\footnotetext{
${ }^{210}$ Probablemente se refiera a la Crónica del Rey Don Juan de Aragón, segundo de este nombre, Valencia 1541 . No creemos que se trate de la Crónica de Juan segundo de Castilla y León, Logroño 1517.

${ }^{211}$ Fuster, Melchor, los «Discursos» probablemente se refiera a: Disputationes Voluntae Dei, También Misceláneas predicables políticas y morales. Doctor en teología y sacerdote. Valencia, en casa de Nogués, 1650.

212 Garau, Francisco, El sabio instruido de la naturaleza, en quarenta máxima políticas y morales ilustradas con todo género de erudición sacra y profana. Barcelona 1675.

${ }^{213}$ Fulvio, Valerio, Avviso di Parnaso nel quale si racconta la povertá, e miseria, dove é giunta la Republica di Venetia et il Duca di Savoia. Scritto da un curioso novellista Spagnuolo. Antopolia 1618. Es un ataque a los españoles y al duque de Osuna.

${ }^{214}$ Granada, Fray Luis, Obras completas. Diversas ediciones: la de Matías Gast Salamanca 1583, la de Madrid $1676 . .$.

${ }^{215}$ Granada, Fray Luis de, Introducción al símbolo de la fe, Salamanca 1582.

${ }^{216}$ San Agustín, Confesiones traducidas del latín en romance castellano, por fray Sebastiano Toscano. En Salamanca por Andrés Portonaris, 1551, 1. ${ }^{2}$ Edición

${ }^{217}$ Mena, Juan de, Laberinto de fortuna o las Trescientas. Tordesillas 1444

${ }^{218}$ Lope de Vega. D. Felix, Jerusalén Conquistada, Madrid 1609.

219 Tasso, Torcuato, Jerusalén libertada. Traducciones: Juan Sedeño (Madrid 1587), Antonio Sarmiento de Mendoza (Madrid 1649).

${ }^{220}$ Guevara, Fray Antonio de, Menosprecio de Corte y Alabanza de Aldea, Valladolid 1538.

${ }_{221}$ Manrique, Jorge, Coplas a la muerte de su padre, Zamora 1480.

222 Véase nota n. ${ }^{\circ} 64$.

223 Plutarco de Queronea, Obras Morales, Alcalá de Henares, 1548.

${ }^{224}$ Quizá se refiera a: Filantes, D. Felipe, Advertencias a los Reyes y Príncipes, sin lugar 1611.

${ }^{225}$ Van der Hamen y León, Lorenzo, Felipe, el prudente, segundo de este nombre. Madrid 1625. Hermano del famoso pintor Juan de van der Hamen y amigo de Lope de Vega.

${ }^{226}$ Porreño, Baltasar, Los dichos y hechos del Rey Felipe II, Cuenca 1621.

${ }_{227}$ Quizás refiera a: Martyr Moixet, Pedro, Dietario Virginal, en el qual los devotos a María hallarán muchos ejemplares de todos estados, Barcelona 1642.

${ }^{228}$ Casanova, José de, Primera parte del arte de escribir todas las formas y letras, escrito y tallado por el mismo, Madrid 1650. Otro libro interesante es, Ocho ideas de la pintura fabulosa, Madrid 1649.

${ }^{229}$ Existen diversas impresiones con este título en los siglos xvi y xvil. Quizá pueda ponerse en relación con, Janua, Máximas, sentencias y refranes castellanos, Salamanca 1611. En latín y castellano.

${ }^{230}$ Nebrija, Antonio de, Vocabularium Antonii Nebrissensis, VV ediciones. La más antigua en dos tomos, latino-español y español-latino de 1492, 1495, en Salamanca.
} 
- Dos vocabularios italianos y castellano (en $4 .^{\circ}$ ) (Cano - Salvador) 230 bis

- Gramatica griega (en $80^{\circ}$ ) (Cano - Salvador)

- Practica de la Perspectiva de Viñola ${ }^{231}$ (Cano - Salvador)

- Arquitectura de Vítrubio en italiano (Cano - Salvador)

- "de Sebastiano ${ }^{232}$ (Cano - Salvador)

- " de Pietro Cataneo ${ }^{233}$ (Cano - Salvador)

— " de Viñola ${ }^{234}$ (Cano y Salvador)

- " de Viola en italiano ${ }^{235}$ (Cano y Salvador)

_ " de Juan Antonio Rusconi ${ }^{236}$ (Cano - Salvador)

- Una arquitectura de Biñola ${ }^{237}$ (Cano y Salvador)

- Regule Generale de Arquitectura (Cano - Salvador) ${ }^{237 \text { bis }}$

- Palladio de Arquitectura ${ }^{238}$ (Cano - Salvador)

- Libro de Antonio Labaco de Arquitectura ${ }^{239}$ (Cano - Salvador)

- Los diez libros de arquitectura de Alberti en Italiano (en $4 .^{\circ}$ ) ${ }^{240}$ (Cano - Salvador)

- Perspectiva practica (tres tomos) (Cano - Salvador) ${ }^{240 \text { bis }}$

— " " de Pietro Aconti en italiano ${ }^{241}$ (Cano - Salvador)

- Practica de la perspectiva de Lorenzo Sirigati ${ }^{242}$ (Cano - Salvador)

_ " " de Daniel Barbaro ${ }^{243}$ (Cano - Salvador)

- Juan de Arfe de Arquitectura y escultura ${ }^{244}$ (Cano - Salvador)

- Arte y uso de arquitectura del padre Laurencio, $10^{\circ}$ y $2 .^{\circ}$ tomo ${ }^{245}$ (Salvador)

- Sagredo medidas de Romano (en $\left.8 .^{\circ}\right)^{246}$ (Cano - Salvador)

- Marte Frances ${ }^{247}$ (Cano - Salvador)

- Filomena de Lope de Vega (en $\left.4 .^{\circ}\right)^{248}$ (Cano - Salvador)

- Estilo de escrivir cartas (en $\left.8 .^{\circ}\right)^{249}$ (Cano - Salvador)

- Boca de todas verdades (en $8 .^{\circ}$ ) (Cano - Salvador)

230 bis Franciosini, Lorenzo, Vocabulario español e italiano, 2 vols. Roma, 1620, 1633...

${ }^{23}$ | Vignola, Jacopo Barozzi da, Le due regole della prospetttiva pratica, Roma 1583, 1. edición de Danti.

${ }^{232}$ Serlio, Sebastiano, Los siete libros de arquitectura, Edición completa, preparada por Sacamozzi, Venezia, Franceschi, 1584, 1600, 1618; París, 1645. Edición española traducida por Francisco de Villalpando. Toledo 1552.

${ }^{233}$ Cattaneo, Pietro, I quattro primi libri d'architettura, Venezia 1554.

${ }^{234}$ Vignola, Jacopo Barozzi da, Regole degli cinque ordini d'architettura in 32 tavole, Edición príncipe 1562, Venecia, 1570, 1582, 1596; Roma 1602; Madrid, 1593 y 1630 (de Patricio Cavexi).

${ }^{235}$ Viola Zanini, G., Della Architettura... libre due, Padova, 1629.

${ }^{236}$ Rusconi, Giovanni Antonio, Dell'architettura secondo i precetti del Vitruvio, libri X, Venezia 1590.

${ }^{237}$ Véase nota $n^{\circ}{ }^{\circ} 234$.

237 tis. Serlio, S., Regoli generali di architettura sopra la cinque maniere de gli edifici..., Venecia, 1537.

${ }^{238}$ Palladio, Andrea, I quattro libri dell'Archittetura, Venezia 1570 edición príncipe. Abundantes ediciones posteriores.

En español, traducción de Francisco de Praves (solamente el primer libro), Valladolid, 1625.

${ }^{239}$ Labacco, Antonio, Libro appartenente all'Architettura, Roma 1552.

${ }^{240}$ Alberti, Leon Battista, De re aedificatoria, Firenze 1485, Edición príncipe dedicada a Lorenzo el Magnífico. Traducción italiana de Pietro Lauro, Venezia 1546, y la de Cosimo Bartoli, la más utilizada, Florencia 1550.

240 bis Pudier corresponder tanto a Danti, Egnazio, La Prospettiva di Euclides, Firenze, 1553 o a la obra de Vredeman de Vries, Arquitectura et perspectiva theorica ac practica, Lyon, 1599.

${ }^{241}$ Accolti, Pietro, Lo inganno degli occhi, prospettiva pratica, trattato in acconcio della pittura, Florencia 1625.

${ }^{242}$ Sirigatti, Lorenzo, La pratica della prospettiva, al Sermo Ferdinando Medici Gran Duca di Toscana, Venezia, 1569.

${ }^{243}$ Barbaro, Daniele, Prattica della prospettiva... opera molto proffitevole a' pittori, sculttori e architetti, Venezia 1569.

${ }^{244}$ Arphe, Juan de, De varia commensuracion para la Esculptura y Architectura, Sevilla 1585.

${ }^{245}$ San Nicolás, Fray Lorenzo de, Arte y uso de la Architectura, Madrid 1633; Segunda parte del arte y uso de architectura, Madrid 1665, 1667.

${ }^{246}$ Sagredo, Diego del, Medidas del romano, Toledo 1520.

${ }^{247}$ Patricio, Alejandro, Marte Francés o la justicia de las armas, y confederación del Rey de Francia. Madrid 1637.

${ }^{248}$ Vega y Carpio, Félix Lope de, La Filomena, con otras diversas rimas, prosas y versos. Madrid 1621.

${ }^{249}$ Probablemente se trate de: Leras, Juan de, Estilo de escribir cartas. Zaragoza 1569. 
- Casado de satisfacion (en $80^{\circ}$ ) ${ }^{250}$ (Salvador)

- San Isidro de Lope (en 8. ${ }^{\circ}{ }^{251}$ (Cano - Salvador)

- Catequismo ${ }^{252}$ (Cano - Salvador)

- Explícacion del Padre Nuestro ${ }^{253}$ (Salvador)

- Union de Portugal y Castilla ${ }^{254}$ (Cano - Salvador)

- Sintinela contra judios (Cano - Salvador)

- Constituciones de las monjas capuchinas ${ }^{255}$ (Cano - Salvador)

- Remedios contra escrupulos ${ }^{256}$ (Salvador)

- Desengaño de la Fortuna (en $\left.8 .^{\circ}\right)^{257}$ (Cano - Salvador)

- Idea de Amistat (Cano - Salvador)

- Ideal del Predicador (Cano - Salvador)

- Vision deleitable ${ }^{258}$ (Cano - Salvador)

- Casos raros de la confesion ${ }^{259}$ (Salvador)

- Sima del Parnaso (Cano - Salvador) ${ }^{260}$

- Paratodos de Montalvan (Cano - Salvador) ${ }^{261}$

- Filotea de Palafoix (en 8. ${ }^{\circ}$ ) (Salvador)

- Resumen historial (Cano - Salvador)

- Seneca y Neron (en 8..$^{\circ}$ (Cano - Salvador)

- Merlini Cocali (Cano - Salvador)

- Memoria de Margarita de Austria (Cano,- Salvador) ${ }^{262}$

- Arte de gramatica española, $\left(8 .^{\circ}\right)$

- Tesoro de la lengua latina o española ${ }^{263}\left(4 .^{\circ}\right)$ (Cano - Salvador)

- Tesoro de las tres lenguas

- Inquisidion (?) de los verbos $\left(4^{\circ}\right.$ )

- Comandinus in Apolonium et alios Adriano Romano apologia pro arquimede;

- Efemerides de Argonio desde el año 1671 hasta $1700^{264}\left(4 .^{\circ}\right.$ ) (Salvador)

- Tholomeus Parus de Argonio ${ }^{265}\left(4^{\circ} .^{\circ}\right.$ ) (Salvador)

- Suplementum efemerides Maquini (4. ${ }^{\circ}$ )

- Efemerides de March Antonio seleste ${ }^{266}$ en foleo (Cano - Salvador)

- Efemerides de Argoli tres tomos ${ }^{267}$ (Cano - Salvador)

- Argoli Tabula primi ad latitudem gradi trigessimo primo usque ad sexagessimum (4..$\left.^{\circ}\right)$

- Efemerides de Silva (4. $\left.{ }^{\circ}\right)$

${ }^{250}$ Casado, Jerónimo, De Satisfación, Valencia 1541.

25. Vega y Carpio, Félix Lope de, Vida del bienaventurado Isidro, Madrid 1599.

252 Existen unas diez impresiones de catecismos entre los siglos XVı y XVII.

25,3 Catalá de Monsonis, Fray Gaspar, Explicación sobre la Oración del Padre Nuestro, Valencia 1667.

${ }^{254}$ Silva, Juan de, Conde de Portalegre, Historia de la unión del reino de Portugal a la corona de Castilla, escrita por Jerónimo Franchi...... Traducido en lengua castellana por D. Luis de Bavia. Barcelona 1610. Libro muy célebre en la época que fue traducido a varias lenguas y no fue escrito por Jerónimo Franchi.

${ }^{255}$ Merinero López, Juan, Constituciones para monjas y religiosas sujetas a la orden de N.P.S. Francisco. Sin lugar 1642.

${ }^{256}$ Probablemente se refiera a: Cabrera, Fray Alonso de, De los escrúpulos y de sus remedios, Valencia 1599.

${ }^{257}$ Marqués de Careaga, Gutierre, Desengaño de fortuna muy provechoso y necesario para todo género de gentes y estado, Barcelona 1611 .

${ }^{258}$ No tenemos seguridad de que obra puede referirse: Torre, Alfonso de la, Visión delectable, Burgos 1485, sobre la filosofía y otras ciencias; Picolomini, Aeneas Silvus, Visión deleitable de la casa de la fortuna, Valencia 1611; Gamis, Juan, Visión deleitable de la casa de la fortuna, Valencia 1611.

${ }^{259}$ Sanvitores y Alonso de Maluenda, Diego Luis \& Vega, Cristóbal, Casos raros de la confesión, Valencia. Comenzado por Cristóbal y terminado por Diego Luis.

260 Litala y Castellví, D. José de, Cima del Monte Parnaso español con las tres Musas castellanas, Caliope, Urania y Euterpe, Caller, 1672.

261 Pérez de Montalbán, J., Para todos, Madrid, 1632, sátira contra Quevedo.

262 Guzmán, Diego de, Vida y muerte de Doña Margarita de Austria, Reyna de España..., Madrid, 1617. 
- Efemerides estadij, dos tomos. (4..$\left.^{\circ}\right)$

- Novus comentarius in equatorem planetarum $\left(4 .^{\circ}\right)$

- Astronomia varia en latin $\left(4 .^{\circ}\right)$

- Tabula Monte Regii ${ }^{268}\left(4 .^{\circ}\right)$ (Cano - Salvador)

- Guidi baldi Mecanicorum ${ }^{269}$ (Cano - Salvador)

- Agricultura cristiana de Pineda dos tomos

- Coronica del mundo antiga ${ }^{270}$ (Cano - Salvador)

- Coronica de Español de Carbonell antiga

- Coronica de los moros

- Coronica de la religion de San Juan, $1 .^{\circ}$ y $2 .^{\circ}$ parte

- Coronica de los reyes de Aragon ${ }^{271}\left(4^{\circ}\right.$ ) (Cano - Salvador)

- Anales de Flandes de Sueiro $2721 .^{\circ}$ y $2 .^{\circ}$ tomo (Cano - Salvador)

- Anales de Carrillo ${ }^{273}$ (Cano-Salvador)

- Historia de Tortosa ${ }^{274},\left(8^{\circ}\right)$ (Cano - Salvador)

- Historia de Leon ${ }^{275}\left(4 .^{\circ}\right)$ (Cano - Salvador)

- Historia del Rey Alfonso antiga ${ }^{276}$ (Cano - Salvador)

- Historia de Cayo Plinio ${ }^{277} 1 .^{\circ}$ y $2 .^{\circ}$ tomo (Cano - Salvador)

- Historia de Carlos Quinto ${ }^{278}$ dos tomos (Cano - Salvador)

- Historia de San Diego ${ }^{279}$ (Cano - Salvador)

- Historias de Paulo Xobio ${ }^{280}$ (Cano - Salvador)

- Elogios de Paulo Xobio

- La fundacion de Roma y guerra africana de Tito Livio ${ }^{281}$ (Cano - Salvador)

- Memorias de Felipe de Comines ${ }^{282}$ (Cano - Salvador)

\footnotetext{
${ }^{263}$ Covarrubias, S. Madrid, 1611 o quizá Moles, Gaspar, Zaragoza, 1646.

${ }^{264}$ Argoli, Andreae, Ephemerides iuxta tychonis hypoteses et Coeli deductas observationes, Lyon, 1649.

${ }^{265}$ Argoli, Andreae, Ptholomeus Parvus: in genethiacis iunctus arabibus, Lugduni, 1659.

${ }^{206}$ Gio Ant. ${ }^{\circ}$ Magini, Efemerides de los movimientos celestes desde 1606 hasta 1630, Venecia, 1581, 1609, en fol.

${ }^{267}$ Argoli, Andreae, Ephemerides iuxta tychonis ...., Lyon, 1641.

268 J. Müeller-Regio Montano-, Astronomia, s.1.; s. a.

${ }^{269}$ Guido Ubaldi, Liber Mecanicorum, Pésaro, 1577, Venecia, 1581. No se registran ediciones españolas.

${ }^{270}$ Giacomo Filippo Foresti, Suma de todas las Cronicas del mundo llamado en latín Suplementu Cronicarum, Valencia, 1510.

${ }^{271}$ Fabricio, Gauberto, Coronica de los reyes de Aragón, 1. a edic. Zaragoza, 1499, en folio.

${ }^{272}$ Sueyro, Manuel, Anales de Flandes o Sitio de Breda rendida a las armas del Rey Phelipe IV, Amberes, oficina Plantiniana, 1626. Obra dedicada a la archiduquesa Isabel, es un relato fiel de las prácticas militares del asedio y glorificación del éxito. Contiene diversos grabados sobre madera y aguafuerte junto a mapas y planos del sitio de Breda. Sueyro, nacido en Amberes fue autor de Breve descripción de Holanda (1622) además de traductor de Salustio y Tácito, y de la obra de Hernan Hugo Obsidio Bredana cuyo frontispicio compuso Rubens.

${ }^{273}$ Carrillo, Martín de, Anales y memorias cronologicas: contienen las cosas mas notables assi eclesiasticas como seculares sucedidas en el modo señaladamente en España desde su principio y población hasta el año MDXX. Huesca, 1622, Zaragoza, 1643.

${ }^{274}$ Martorell, F. Historia de la Ciudad de Tortosa y de la Santa Cinta que dió la Virgen Nuestra Señora a la dicha Ciudad, Tortosa, 1628 , en $8 .^{\circ}$.

${ }^{275}$ Lobera, Athanasio, Historia de las grandezas de la muy antigua, e Insigne ciudad e Iglesia de León, Valladolid, 1596.

${ }_{276}$ Ocampo, Florian de, Las cuatro partes enteras de las crónicas de España que mandó componer el rey D. Alfonso el Sabio, Zaragoza, 1541.

${ }^{277}$ Historias Naturalis ... Venezia, 1476, Historia Natural edic. traducida y ampliada por Gerónimo Huerta, dos tomos, Madrid, 1624.

${ }^{278}$ Vera y Zúñiga, J. A. Epítome de la vida y hechos del invicto emperador Carlos V, Madrid, 1624.

${ }^{279}$ Mata, F. Gabriel de, Vida, muerte y milagros de S. Diego de Alcalá, Madrid, 1598.

${ }^{280}$ Libro de las Historias de Paulo Jovio, Valencia, Joan de Mey, 1562.

${ }^{281}$ Romanae Historiae, Francoforti an Maenum, 1568, con estampas en tabla.

${ }^{282}$ Commines, Felipe de, Memorias de Felipe de Commines Señor de Argenton de los hechos y empresas de Luis undecimo y Carlos octauo, reyes de Francia, traducido del francés por D. Juan Vitrian, dos tomos, Amberes, 1643.
} 
- La Mota Cavalleria de Santiago ${ }^{283}\left(4 .^{\circ}\right)$ (Cano - Salvador)

- Guerra de Inglaterra

- Comentarios Reales de Perú ( 1 y $2 .^{\circ}$ parte)

- Viage de Tierra Santa ${ }^{284}\left(8^{\circ}\right)$ (Salvador)

- Tabla de la monarquia eclesiastica ${ }^{285}, 6$ tomos (Cano-Salvador)

- Descripcion general de Africa ${ }^{286}$ (Cano - Salvador)

- Poblacion de España ${ }^{287}\left(4 .^{\circ}\right)$ (Cano - Salvador)

- Seneca ilustrado con estampas ${ }^{288}$ (Salvador)

- Ritreto de la Casa de Moncada ${ }^{289}$ (en 4. ${ }^{\circ}$ ) (Cano - Salvador)

- Morliani Romano ${ }^{290}$ (Cano - Salvador)

- Vida de Elio Sejano

- Vida de San Francisco Xavier (4..$^{\circ}$

- Vida del poeta Petrarca

- Vida de San Alberto ${ }^{291}$ (Salvador)

- Vocasio Mujeres ilustres, antiga ${ }^{292}\left(4^{\circ}\right)$ (Cano - Salvador)

- Caida de principes ${ }^{293}\left(4 .^{\circ}\right)$ (Cano - Salvador)

- Aviso del Parnaso y trabaxo Vocatini dos tomos ${ }^{294}$ (4..$^{\circ}$ ) (Salvador)

- Eraclito y Democrito ${ }^{295}\left(4^{\circ} .^{\circ}\right.$ (Cano - Salvador)

- Lucano en romance

- Conjuracion de Catelina ${ }^{296}\left(8^{\circ}\right)$ (Cano-Salvador)

- Persilis Segismunda ${ }^{297}\left(4 .^{\circ}\right)$ (Cano-Salvador)

- El escudero Bregon ${ }^{298}\left({ }^{\circ} .^{\circ}\right)$ (Cano - Salvador)

- La picara Justina $\left(8 .^{\circ}\right)^{299}$ (Cano - Salvador)

- El pastor de nochebuena ${ }^{300}$ (Salvador)

- El despertador que avisa

- El mayor mal de los males (8..$\left.^{\circ}\right)$

- Pastores de Belen ${ }^{301}\left(4 .^{\circ}\right)$ (Cano - Salvador)

- Obras de Joan de Mena (8. $\left.{ }^{\circ}\right)$

- Obras de Graciano (4..$^{\circ}$

\footnotetext{
${ }^{283}$ La Mota, Diego de, Libro del principio de la orden de la caballeria de Santiago, Valencia, 1599.

${ }^{284}$ Fray Antonio del Castillo, El Devoto Peregrino, Viage de Tierra Santa. Madrid, Imp. Real. 1654.

${ }^{285}$ Pineda, J., Tabla de la monarquia eclesiastica o Historia universal del mundo.,, treinta tomos, Salamanca, 1588, Barcelona, $1606,1620$.

${ }^{286}$ Mármol, Luis del, Descripcion General de Africa, Granada, 1573, folio, dos tomos

${ }^{287}$ Fray Gregorio de Argaiz, Población Eclesiástica de España, s.l.; s.a.

${ }^{288}$ Lucio Anneo Séneca ilustrado con blasones politicos y morales por Don J. Baños de Velasco y Acevedo, Madrid, $1670,4 .^{\circ}$

${ }^{289}$ Pudiera tratarse de Moncada, D. Francisco, Genealogia de la Casa de los Moncada, publicado en Historia de Bearne, París, 1640.

${ }^{290}$ Marliano, Bartolome, Urbis Romae topographia, Roma, 1544. Descripción de Roma dividida en cinco libros que tratan de su origen y descripció de la urbe, sus lugares y monumentos.

${ }^{291}$ Pudiera corresponder a Roya, Fr. Juan Bta, Vida y milagros de San Alberto, Valencia, 1668.

${ }^{292}$ Bocaccio, G., Las Mujeres Ilustres, Zaragoza, 1494.

${ }^{29.3}$ Boccaccio, G., Cayda de principes, Alcalá de Henares, $3 .^{\circ}$ edic. 1552.

${ }^{294}$ Bocalini, Traiano, Avisos del Parnaso de Traiano Bocalini, primera y segunda centuria, traducción de la lengua toscana a la española por Diego Diaz de la Carrera, Madrid, 1653.

${ }^{29.5}$ López de Vega, A. de, Heraclito y Demócrito de nuestro siglo, Dialogos morales ..., Madrid, $1641,4{ }^{\circ}$.

${ }^{296}$ Cayo Salustio, Conjuración de Catilina, Turín, 1494.

${ }^{297}$ de la Cuesta, Juan, Los trabajos de Persiles y Segismunda, Madrid, 1617.

${ }^{298}$ Espinel, Vicente, Vida del escudero Marcos de Obregón, 1618.

${ }^{2 *}$ Atribuida a Francisco López de Ubeda, La picara Justina, 1605.

${ }^{300}$ Palafox y Mendoza, J., El pastor de noche buena: practica breve de las virtudes ... Valencia, 1646.

${ }^{301}$ Lope de Vega, Pastores de Belen, 1612.
} 
- Obras de Fray Juan de la Cruz

- Obras de Santa Gertrudis, dos tomos (4..$\left.^{\circ}\right)$

- Obras del padre Eusebio, ${ }^{302}$ tres tomos (Cano - Salvador)

- Gobernador cristiano (primer tomo) ${ }^{303}$ (Cano - Salvador)

- Triunfos de Christo de la Aysa

- Epistolas familiares de D. Antonio de Guevara ${ }^{304}$ (Cano-Salvador)

- Epistolas de San Geronimo en romance antigas ${ }^{305}$ (Salvador)

- Jovar de vera et falsa gloria

- Año Santo de la madre Lucia Magdalena de Jesus, (4. $\left.{ }^{\circ}\right)$

- Explicaciones de la bula de Rodrigues ${ }^{306}$ (Cano - Salvador)

- Instruccion de un cristiano (8. $)$

- Alelio moral ${ }^{307}\left(8 .^{\circ}\right)$ (Salvador)

- Davit arrepentido ${ }^{308}$ (Salvador)

- El Hijo de Davit perseguido tres tomos ${ }^{309}\left(4 .^{\circ}\right)$ (Salvador)

- Fray Domingo de Jesus

- Corte Santa (siete tomos)

- Corte en aldea $\left(4 .^{\circ}\right)$

- Silva de sufragio (4..$\left.^{\circ}\right)$

- Origen de las pavordias de Valencia $\left(8 .^{\circ}\right)$

- Excelencias de Nuestra Señora $\left(8 .^{\circ}\right)$

- Bienes de la Diosidad ${ }^{310}\left(4 .^{\circ}\right)$ (Cano - Salvador)

- Combate de Job con el demonio $\left(4 .^{\circ}\right)$

- Tratado de indulgencias ( $\left.8 .^{\circ}\right)$

- Espejo de bienhechores y agradecidos ${ }^{311}$ (Cano - Salvador)

- Contentus mundi $\left(8 .^{\circ}\right)$

- Posa de bien morir $\left(8 .^{\circ}\right)$

- El Rey Nuestro por la provincia de la Cia de Jesús

- Advertencias a la historia del Padre Joan de Mariana de la Cia. de Jesús ${ }^{312}$ (Cano - Salvador)

- Lagrimas de los justos

- Dolsuras del morir

- Almustasaf $\left(8 .^{\circ}\right)$

- Presagios fatales $\left(8 .^{\circ}\right)$

- Heretica de perfeccion $\left(8^{\circ}\right)$

\footnotetext{
${ }^{302}$ Nuremberg, Eusebio, Oculta filosofia. De la sympatia y antipatia de las cosas, artificio de la Naturaleza y noticia natural del mundo... Madrid, 1638.

303 Fray Juan Marquez, El gobernador cristiano deducido de la vida de Moises y Josue, Salamanca, 1612.

${ }^{304}$ Guevara, Antonio, Epistolas familiares, Alcalá de Henares en casa de Juan Gracian, 1600, Madrid, 1668.

${ }^{305}$ Pudiera ser Epístolas de S. Hieronymo, trad. del Bachiller Juan de Molina, dedicada a Doña Maria Enriquez de Borja, Duquesa de Gandia y «aora en el mesmo lugar Abadessa dignisima de Santa Clara», Valencia, imp. Juan Jofre, 1520.

${ }^{306}$ Rodrigues, Manuel, Explicación de la bula de la Santa Cruzada y de las clausulas de los jubileos ... Salamanca, 1602; 1607; Valencia, 1610.

${ }^{307}$ Polo de Molina, S. J., Gobierno moral a Lelio, Murcia, 1657.

${ }^{308}$ Lozano, Cristóbal, El rey penitente David arrepentido, 1656. Trilogía ascético-histórica junto con el posterior y el $n .^{\circ}$ 163 de notas a pie de página.

${ }^{309}$ Lozano, Cristóbal, edic. 1652,1659 y 1661 . Ver nota anterior.

${ }^{310}$ Guzmán, Pedro de, Bienes del honesto trabajo y daños de la ociosidad en ocho discursos, Madrid, 1614, 4..

${ }^{31}$ Espejo de bienhechores y agradecidos que contiene los siete libros de Beneficios de L. A. Seneca traducidos por Fray Gaspar Ruiz de Montiano, 1606, Barcelona, Madrid, 1627, 4.․

${ }^{312}$ Mantuano, Pedro, Advertencias a la Historia del P. Mariana, Toledo, 1601, Madrid, 1613, en 4.․
} 
- Prado Espiritual ${ }^{313}$ (Cano - Salvador)

- Patrocinio espiritual de Andrade ${ }^{314}$ (Salvador)

- Mesa Franca ( 1 y $2 .^{\circ}$ tomo)

- Perfecto prelado dos tomos de Maldonado ${ }^{315}$

- Discrepcion de Botero ${ }^{316}$ (Cano - Salvador)

- Leyes divinas $\left(8^{\circ}\right)$

- Filosofia y logica

- El filosofo natural $\left(4 .^{\circ}\right)$

- Desengaño filosofia moral $\left(4^{\circ}\right)$

- Discurso de la juventud (8..$\left.^{\circ}\right)$

- Comentarios de los españoles (4. $\left.{ }^{\circ}\right)$

- Castilla politica $\left(4 .^{\circ}\right)$

- Pedaço de razon y estado

- El consejero de monarquias

- Del Senado y de su principe ${ }^{317}\left(4 .^{\circ}\right)$ (Cano - Salvador)

- Ayo maestro de principes $\left(4 .^{\circ}\right)$

- Ludovico Blosio ${ }^{318}$ (Cano - Salvador)

- Secretario y consejero de señores y ministros

- Máximo y marco de Vita $\left(8 .^{\circ}\right)$

- Excelencias del nombre de Jesus ${ }^{319}$ (Cano - Salvador)

- Palafox luz de los vinos (sic)

- Palafox consejo del Rey

- Escuela de principiantes $\left(4 .^{\circ}\right)$

- Primera parte de Cortes valerosas $\left(4 .^{\circ}\right)$

- Enquiridron de los tiempos $\left(8^{\circ}{ }^{\circ}{ }^{320}\right.$ (Cano - Salvador)

- Fracasta rey, $\left(8^{\circ} .^{\circ}\right)$

- Las eroticas ${ }^{321}$ (Cano - Salvador)

- Soria (?) perseguida, $\left(4 .^{\circ}\right)$

- Sucesos del año mil seiscientos treinta y nueve en romano

- Sentinela contra judios

- Boca de todas las verdades

Ittem troba recaure en bens de dites tutela, cura y herencia les bens seguents:

Primo una chanverga eo justacor de pell de gamell usat

Ittem un coleto usat

Item un tínter y arener de bronce

Item un compas del mateix

Item unes tisores de tallar paper

${ }^{313}$ Sanctoro, Basilio, Prado Espiritual, Burgos, 1588, a folio.

314 Pudiera ser la obra de Andrade, Alonso de, Milicia espiritual, Madrid, 1662.

${ }^{315}$ Maldonado, Fray Pedro, Discurso del Perfecto Privado. Escribiole el Padre ... de la Orden de San Agustin, Confesor del Duque de Lerma.

${ }^{316}$ Ver entrada n. ${ }^{\circ} 166$. Forma parte de Razón destado (sic) con tres libros de la grandeza de las ciudades. 1 . Ciencia politica. 2. Ciudades. Descripción, Burgos, 1603.

${ }^{317}$ Madariaga, Juan de, Del Senado y de su principe, Valencia, 1617 , en $4 .^{\circ}$. Su autor era monje de la Cartuja de Portaceli, en Valencia.

${ }^{318}$ Las obras de Ludovico Blosio Abad de San Benito, Gerona, 1619, Barcelona, 1621.

${ }^{319}$ Fray Gerónimo Cantó, Excelencias del nombre de Jesús, Barcelona, 1607.

${ }^{320}$ Erasmus, Desiderius, Enchiridion militis christiani..., Compluti., 1525, en 8..

321 Villegas, Esteban M. De, Las Eróticas, Nájera, 1617. 
Item un peset de coure ab ses onces y lliures de ferro

Item sis paletes de fusta pera pintar

Item cinch dotsenes de pincelis de gos

Item tres dotsenes de pincells de melonsillo

Item dos " " de gorrio

Item un llibre en quaranta estampes

Item un modelo de un sepulcre

Item huyt potets de vidres ab diverses sendres pera pintar

Item una capa de vaieta de dos usada

Item nou cadires de repos de Badana negra molt velles

Item sis taburetes de fusta de pi usat

Item trenta modelos de algeps po es caps, peus y mans molt maltratacts.

- Ittem Un belem chiquet de vidre

- Itt. Quatre quadres grans sens guarnisio, lo hu de la Historia de Judic, lo altre de la Reyna Ester, lo altre del Glorios Sent Sebastia y lo altre de los tres Reyes.

- Itt. una tauleta pintada en aquella les armes de la Inquisicio

- Quatre quadrets pintats en una vena (?) de pam de liens ço es S. Luis Beltran. S. Gerony, Sta Theresa de Jesus y Sta. Monica

- Itt. un Sent Joan de barro chiquet

- Itt. Una venera de les armes de la Inquisicio de crest alt y uns perfils de or.

Fa nota Francisca Agramunt viuda que Luis Lluna de Xativa devia a dit Vicente Salvador vintydos lliures salvo just conte ... 